

\section{DISCLAIMER}

This report was prepared as an account of work sponsored by an agency of the United States Government. Neither the United States Govemment nor any agency thereof, nor any of their employees, makes any warranty, express or implied, or assumes any legal liability or responsibility for the accuracy, completeness, or usefulness of any information, apparatus, product or process disclosed, or represents that its use would not infringe privately owned rights. References herein to any specific commercial product, process, or senvice by trade name, trademark, manufacturer, or otherwise, does not necessarily constitute or imply its endorsement, recommendation, or favoring by the United States Government or any agency thereof. The views and opinions of authors expressed herein do not necessarily state or reflect those of the United States Government or any agency thereof. 


\title{
Testing and Evaluation of Light Ablation Decontamination
}

Rick L. Demmer

Russ L Ferguson

Published October 1994

Idaho National Engineering Laboratory

Lockheed Idaho Technologies Company Idaho Falls, Idaho 83415

\author{
Prepared for the \\ U.S. Department of Energy \\ Under DOE Idaho Operations Office \\ Contract DE-AC07-94ID13223
}




\section{DISCLAIMER}

Portions of this document may be illegible in electronic image products. Images are produced from the best available original document. 


\section{ACKNOWLEDGEMENTS}

The author wishes to acknowledge the assistance of Mr. Wayne Griffin, Mrs. Feddy Dickerson, Mr. Wade Warrant, and Ms. Brenda Boyle for their efforts in preparing and analyzing SIMCON coupons. Without their assistance this work could not have been completed. 


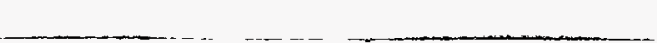

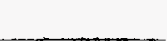

- 


\section{ABSTRACT}

This report details the testing and evaluation of light ablation decontamination. It details WINCO contracted research and application of light ablation efforts by Ames Laboratory. Tests were conducted with SIMCON (simulated contamination) coupons and REALCON (actual radioactive metal coupons) under controlled conditions to compare cleaning effectiveness, speed and application to plant process type equipment. 


\section{CONTENTS}

ACKNOWLEDGEMENTS $\ldots \ldots \ldots \ldots \ldots \ldots \ldots \ldots$ iii ABSTRACT $\ldots \ldots \ldots \ldots \ldots \ldots \ldots \ldots \ldots \ldots \ldots \ldots \ldots \ldots \ldots$

ACRONYMS ...........................

1.0 INTRODUCTION $\ldots \ldots \ldots \ldots \ldots \ldots \ldots \ldots \ldots \ldots \ldots \ldots$

2.0 EXPERIMENTAL METHODS $\ldots \ldots \ldots \ldots \ldots \ldots \ldots \ldots \ldots$

3.0 DISCUSSION OF RESULTS . . . . . . . . . . . . . . . . . . . 8

3.1 Continuous Wave Carbon Dioxide Laser Testing . . . . . . 8 8

3.2 Nd:YAG Laser Testing . . . . . . . . . . . . . 9

3.3 Excimer Laser Tests . . . . . . . . . . . . . . . 12

3.4 Gas Environment, Lens and Surface Coating Effect on Ablation . 16

3.5 Application of Light Ablation to Hot Cell Equipment . . . . . . 19

4.0 SUMMARY OF RESULTS $\ldots \ldots \ldots \ldots \ldots \ldots \ldots \ldots \ldots$

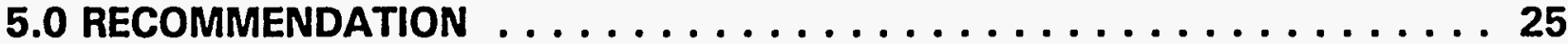

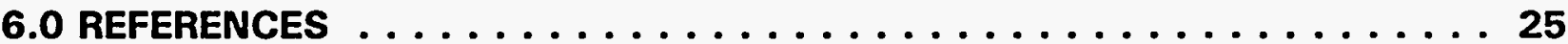

APPENDIX A

Calculation of Decontamination Times . . . . . . . . . . . A1

APPENDIX B

Cost of Capital Equipment . . . . . . . . . . . . . . B1 


\section{SUMMARY}

This report covers experimental work comparing three different types of lasers for use in light ablation decontamination. Comparisons are made on the basis of speed, effectiveness, cost and overall application to plant equipment. These evaluations are developed for the $\mathrm{CO}_{2}$ laser, Excimer laser and the Neodymium:Yttrium, Aluminum, Garnet (Nd:YAG) laser. One laser ( $\mathrm{cW} \mathrm{CO}_{2}$ laser) was eliminated at the early stages of ablation research due to apparent excessive metal melting. The melting was accompanied by metal distortion and possible vaporization of the contaminants. The other two lasers, the Nd:YAG and the Excimer, were deemed acceptable for ablation decontamination, and were further tested and developed for application to ICPP decontamination needs. The tests also included the suitability to remove coatings, examination of off-gas materials and optical development. Decontamination of three types of radioactively contaminated metal samples was completed. The majority of this report is reproduced from reports submitted by Ames Laboratory during the performance of their light ablation research contract. 


\section{ACRONYMS}

$\begin{array}{ll}\mathrm{CO}_{2} & \text { Carbon Dioxide } \\ \mathrm{cm} & \text { Centimeter } \\ \mathrm{CW} & \text { Continuous wave } \\ \mathrm{DF} & \text { Decontamination factor } \\ \mathrm{f.I} & \text { Focal length } \\ \mathrm{FSA} & \text { Fluorinel Storage Area (CPP-666) } \\ \mathrm{Hz} & \text { Hertz - pulses per second } \\ \text { ICPP } & \text { Idaho Chemical Processing Plant } \\ \text { mj } & \text { Millijoules } \\ \text { Nd:YAG } & \text { Neodyneum: Yttrium, Aluminum, Garnet } \\ \text { nm } & \text { Nanometer } \\ \text { ns } & \text { Nanosecond } \\ \text { NWCF } & \text { New Waste Calcine Facility } \\ \text { REALCON } & \text { Radioactive metal coupon samples } \\ \text { SIMCON } & \text { Simulated contamination samples } \\ \text { WINCO } & \text { Westinghouse Idaho Nuclear Company } \\ \text { W } & \text { Watts }\end{array}$




\section{Testing and Evaluation of Light Ablation Decontamination}

\section{0*INTRODUCTION}

Emphasis on the minimization of secondary waste resulting from decontamination has increased because of restrictions on the use of hazardous chemicals and Idaho Chemical Processing Plant (ICPP) waste handling issues. The ICPP Decontamination Development Group has evaluated and introduced new methods of decontamination to help solve the problems of sodium and/or secondary waste generation. Decon Development has performed on-site demonstrations and evaluations of a number of novel decon techniques. Of these varied methods, light ablation satisfies many of the criteria for decontamination.

Light ablation or laser decontamination is the process of removing surface material by heating with localized high intensity light. Two methods are currently employed in light ablation; the first is the laser, a coherent (narrow wavelength) light source, and the second is incoherent (broad wave length) xenon flash lamps. Either method can be pulsed to produce a microsecond heating of surface contaminants to cause vaporization, ablation and scouring of the material. This forms the basis of the decontamination potential for light ablation: the removal of a thin portion of surface contaminants or the surface itself by the controlled application of light energy.

Several investigators are developing methods for performing light ablation. Maxwell Laboratories, suppliers of the Xenon Flash Blast Units, are involved in ablative statuary cleaning.' Hobart Laser Products developed a high power continuous "YAG" laser coupled with fiber optic cables that has been used to ablate paint from bridge structures in Illinois. ${ }^{2}$ Plasma Tronics Company is working with " $\mathrm{CO}_{2}$ " pulse lasers for paint removal work for the U. S. Air Force. ${ }^{3}$ EG\&G Idaho researchers have used ablation with a Laser Photonics laser to produce an ultrasonic test method for U. S. Navy welding equipment. ${ }^{4}$ Currently two researchers are pursuing radioactive decontamination using light ablation. Laser light ablation is used by researchers at the University of Idaho for removing minute amounts of materials for chemical analysis. Dann Flesher at Westinghouse Hanford is developing laser and Xenon Flash Blast equipment for use in radioactive areas. ${ }^{5}$ The most mature decontamination work being performed is directed by Dr. Martin Edelson of Ames Laboratory, a DOE facility operated by lowa State University. ${ }^{6.7}$ 
WINCO (now Lockheed Idaho Technologies Co.) contracted with Ames Laboratory to provide ablation of SIMCON and radioactive coupons because of their expertise in this field. The Ames approach to laser surface decontamination is to use high power, short pulsed, laser beams to decontaminate metals by removing contaminated surface layers. When metals, or other materials such as ceramics and plastics, are exposed to highly localized and intense photon sources, such as a focused laser beam, material is ablated from the surface into the surrounding atmosphere. This "dust" can be collected via HEPA filtration of particulate-laden offgases to prevent deposition back onto the surface or other nearby surfaces. High decontamination factors have been realized in these tests and additional work is being contracted to develop handling and application methods for the light ablation equipment. A priority will be placed on the development of fiber optic delivery systems to replace the mirror and lens arrangement currently used.

The contracted work entailed the testing of several lasers on simulated contamination (SIMCON). WINCO supplied test specimens for Ames to perform decontamination. Ames optimized decontamination methods using their laser equipment and examined gaseous byproducts of the decontamination. They determined decontamination factors and cleaning rates for three different laser wavelengths optimized to power levels, material types and rastering speed. Ames performed tests to determine if some contamination types require preconditioning efforts. Ames also evaluated the applicability of laser systems (mobile and immobile) for remote decontaminations. Light ablation vapor generation, gas stream characterization and evaluation of gas requirements were also completed. Finally Ames simulated decontamination of in-cell equipment to determine setup, decontamination and equipment removal times. Part of the final task provided a preliminary design and estimate of capital and operating costs for a production scale application of light ablation decontamination.

The three lasers chosen for this task span a wide variety of industrial laser types:

1) Carbon dioxide lasers are used commercially in industry for welding and cutting operations. It is a continuous wave (cw) laser that generally is operated in multimode at $10.06 \mu \mathrm{m}$ (i.e., $10,600 \mathrm{~nm}$ ) in the infrared portion of the optical spectrum.

2) Nd:YAG laser: can be operated in $\mathrm{cw}$ or pulsed mode. The laser operates at $1064 \mathrm{~nm}$ in the near-infrared spectrum. This wavelength can be conveniently conveyed by optical fibers, which could be advantageous for operations in highly radioactive areas. Two pulsed Nd:YAG operating modes were available for study. In the first, the Qswitched mode, the laser produced powerful pulses of less than ten 
nanosecond durations. In the second mode, the "free-running" mode, the laser produced pulses of microsecond duration.

3) Excimer lasers are the least mature of the three lasers used in this study. They operate at a variety of laser wavelengths in the ultraviolet portion of the optical spectrum. This excimer laser was operated using a mixture of fluorine and krypton (KrF) gases and produced intense output pulses with an approximately 28 nanosecond duration at $248 \mathrm{~nm}$.

\subsection{EXPERIMENTAL METHODS}

For the first series of evaluations, a $\mathrm{CO}_{2} \mathrm{cw}$ laser (Spectra Physics, Model 820) operated at a wavelength of $10.6 \mu \mathrm{m}$. This laser delivered up to $2000 \mathrm{~W}$ output power with a Gaussian energy distribution. Three different focal length $(64 \mathrm{~mm}, 130$ $\mathrm{mm}$, and $190 \mathrm{~mm}$ ) spherical lenses were used to focus the laser beam. Air was used as a shield gas for lens protection. The estimated power density was approximately $6 \times 10^{5} \mathrm{~W} / \mathrm{cm}^{2}$ at $300 \mathrm{~W}$ output power using a $130 \mathrm{~mm}$ focal length f.l. spherical lens. The laser was interfaced with a worktable that had 5 degrees of freedom, 3 linear and 2 rotational.

A Nd:YAG pulsed laser (Continuum Co., Model YG660) operating at an 1064 $\mathrm{nm}$ lasing wavelength was used for the second evaluation. In Q-switch mode, this laser delivered approximately $190 \mathrm{mj}$ per pulse at a $30 \mathrm{~Hz}$ repetition rate. The output energy of the laser was measured by a power meter (Scientech, Model 350). The laser pulse had an $8 \mathrm{~ns}$ pulse width and the output beam was circular with a $7 \mathrm{~mm}$ diameter. The laser intensity distribution was approximately Gaussian. After the laser beam traveled 3 meters, the diameter expanded to $10 \mathrm{~mm}$. Due to the use of multiple prisms (non-coated) for the laser beam delivery system, only $150 \mathrm{~mJ}$ per pulse reached the focusing lenses. Two different focal length (100 $\mathrm{mm}$ and $200 \mathrm{~mm}$ ) cylindrical lenses were used to focus the laser beam to a line $(10 \mathrm{~mm} \times 0.15 \mathrm{~mm}$ for the $100 \mathrm{~mm}$ f.l. lens and $10 \mathrm{~mm} \times 0.3 \mathrm{~mm}$ for the $200 \mathrm{~mm}$ f.l. lens) on the sample surface. Both lenses were uncoated with about $10 \%$ energy attenuation. The average power density was estimated to be $1.2 \times 10^{9} \mathrm{~W} / \mathrm{cm}^{2}$ at $150 \mathrm{~mJ}$ energy output with the use of $100 \mathrm{~mm}$ focal length cylindrical lens. The sample was positioned on a translational table for rastering.

Fiber optic transmission capability was tested using the Nd:YAG laser. For these tests the laser was operated at $30 \mathrm{~Hz}$, nominal $10 \mathrm{~ns}$ pulse width and $1060 \mathrm{~nm}$ wavelength. A $1 \mathrm{~mm} 3 \mathrm{M}$ Co. laser compatible optical fiber was tested first. The fiber was designed to transmit up to $500 \mathrm{mj} /$ pulse of Q-switched Nd:YAG output. The fibers were polished by hand. A second series of tests were conducted to determine if fibers prepared by the Allied-Signal Co. would increase power transmission. The Allied preparation included annealing the fibers and special end 
polishing and cleaning. Additional modifications were made to position the focal point of the laser inside the fiber and use of a 0.75 aperture for full containment of the beam inside the fiber.

This Nd:YAG laser was also reconfigured to operate in a "free-running" mode with an energy of $50 \mathrm{mj}$ per pulse and a pulse width of $30 \mu \mathrm{s}$. There were tens of pulses emitted in this time envelope. A $200 \mathrm{~mm}$ uncoated spherical lens was used to focus the "free-running" Nd:YAG laser beam to a spot on the target surface. The estimated spot size was $100 \mu \mathrm{m}$ and the average power density was $2.1 \times 10^{7} \mathrm{~W} / \mathrm{cm}^{2}$.

The third series of evaluations was completed with an excimer laser. The excimer laser used in this study was a Questek Co., Model 2560v $\beta$ operating with a mixture of $\mathrm{Kr}$ and $\mathrm{F}_{2}$ in $\mathrm{Ne}$ gases. Upon electronic excitation, the mixture forms an unstable excimer (KrF) that lased at $248 \mathrm{~nm}$. A cryogenic gas processor (Oxford Inst., Model GP2000XM) was used to prolong the gas mixture life and maintain the cleanliness of the optical couplers by removing impurities formed during operation. This laser was rated by its manufacturer to deliver a maximum of $100 \mathrm{~W}$ average output power at $300 \mathrm{~Hz}$ repetition rate when operated at $248 \mathrm{~nm}$. The laser energy output was calibrated monthly by a pyroelectric joulemeter (Scientech, Model PHF50). The pulse width for each laser pulse was $28 \mathrm{~ns}$. The laser output beam had a flat top profile, (non-gaussian), with dimensions of $14 \mathrm{~mm} \times 23 \mathrm{~mm}$. After the laser beam traveled 2 meters to a focusing lens, the dimensions were $20 \mathrm{~mm} \times 30 \mathrm{~mm}(\mathrm{~V} \times \mathrm{H})$. The manufacturer recommended operating the laser at $70 \mathrm{~W}$ average output power or lower for long term operation, i.e., several hours without stopping the laser. For work reported here, the excimer was operated at $50 \mathrm{~W}$ and provided days of operation without the need for gas refills or the cleaning of optical couplers. On occasion, fluorine was injected into the laser to maintain a selected output power level. This operation was easily done without necessitating any downtime. Two different focal length (f.l.) cylindrical lenses $(100 \mathrm{~mm}$ and $200 \mathrm{~mm}$ ) were used to focus the laser beam to a line $130 \mathrm{~mm} \times 0.3 \mathrm{~mm}$ for the $100 \mathrm{~mm}$ f.I. lens and $30 \mathrm{~mm}$ $x 0.6 \mathrm{~mm}$ for the $200 \mathrm{~mm}$ f.l. lens) on the sample surface. The $100 \mathrm{~mm}$ f.I. cylindrical lens was uncoated with $18 \%$ energy attenuation. The $200 \mathrm{~mm}$ f.l. cylindrical lens had a $248 \mathrm{~nm}$ anti-reflection coating on both surfaces and had less than $1 \%$ energy attenuation. The width of the focused laser beam cited previously is an estimate since no reliable method was available for accurately measuring the beam width at the focal plane. The power "density" was estimated to be $1.4 \times 10^{8}$ $W / \mathrm{cm}^{2}$ when using a $100 \mathrm{~mm}$ f.l. lens and $350 \mathrm{~mJ}$ laser pulse energy. The focusing lens was mounted on a Z-translational table so that the focus was controlled by a computer. The material was positioned on an $X-Y$ translational table, which was controlled by a computer.

A schematic design of a particle trapping cell is shown in Figure 1. The cell was mounted on a Z-translational table and was positioned $2 \mathrm{~mm}$ away from the 
target materials. Air (10 to $20 \mathrm{cfm})$ was drawn into the cell through the bottom opening. A quartz window was placed on the top of the cell to transmit the laser beam and to help contain captured particles. There were two gaps between the window and the cell wall to draw air into the cell from the top and protect the window against particulate adhesion. A HEPA (high efficiency particulate air) filter $199: 99 \%$ efficiency for $0.3 \mu \mathrm{m}$ particles) was placed between the cell and the air exhaust blower to trap particulate generated by laser ablation. This trapping system was employed for the studies of excimer laser and Nd:YAG laser ablation.

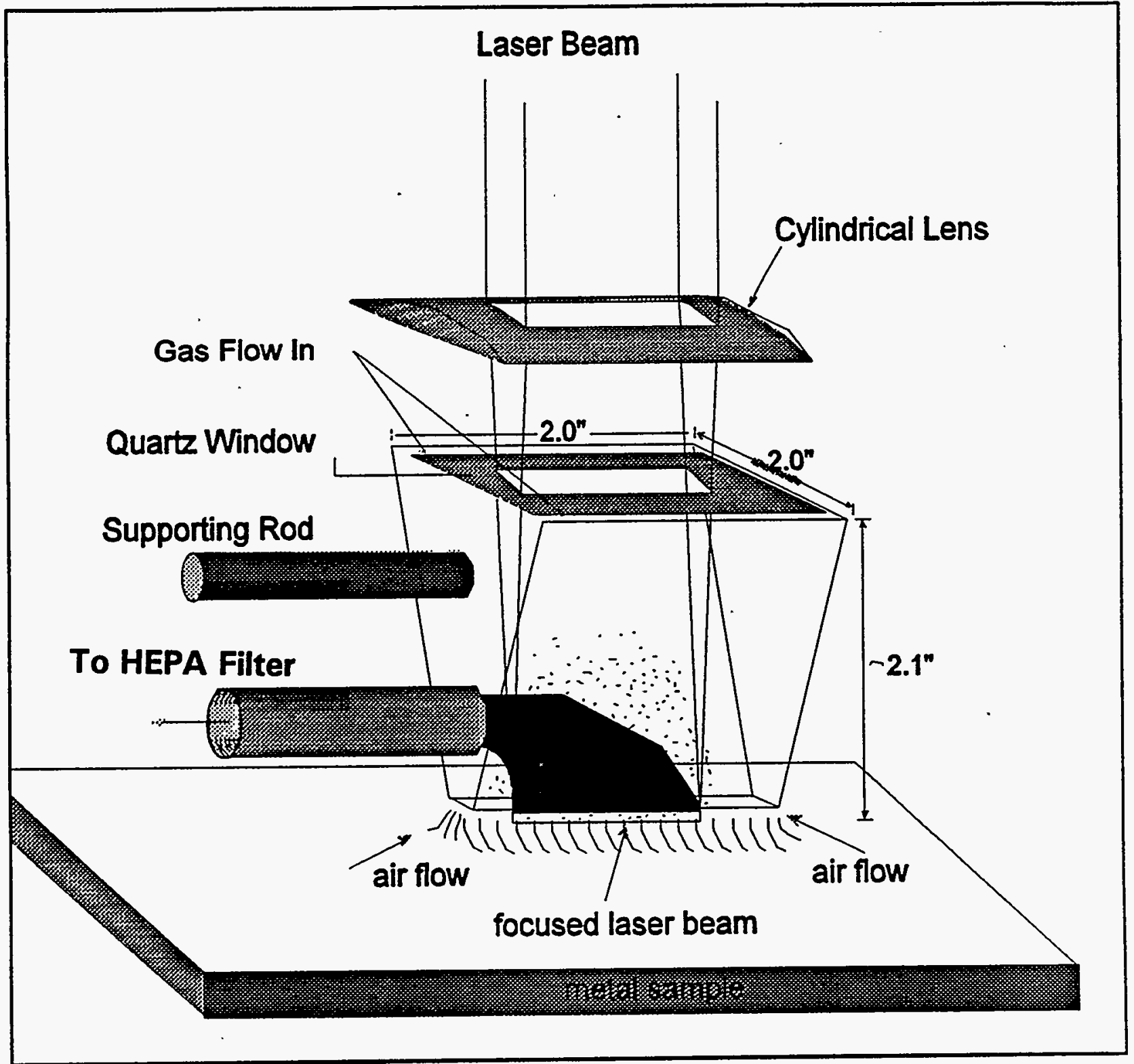

Figure 1, Lens and Collection Cell Used During Laser Ablation Process. 
Metal alloys (aluminum, 304 stainless steel, 316 stainless steel, Inconel 600, copper, and Monel) were obtained from Goodfellow Metals, Inc. WINCO provided metal alloys (Inconel 825, Hastalloy $\mathrm{X}, \mathrm{C} 4$, and $\mathrm{C}-24$ ) and both non-radioactive contaminated samples SIMCON I and SIMCON $1{ }^{8}$ and radioactive samples (REALCON) for testing. No prior treatment was deemed necessary to prepare any sample for laser decontamination. In every case, the laser beam was held stationary while the material was moved by the worktable under computer control. REALCON I samples were cut from a WINCO calciner nozzle that was fabricated from Haynes 25, a hightemperature cobalt-chromium alloy. REALCON 2 samples were $1 "$ square coupons sectioned from a WINCO criticality barrier made of 304 stainless steel.

The full-scale demonstration of laser decontamination was performed on a surplus tank supplied by WINCO. The end-cap of the tank was removed to provide access to the tank interior for decontamination of both the external and internal surfaces using an excimer laser. Since, in a real application, the tank would be located in a restricted environment and manual cutting of the end-cap would be potentially hazardous, a remote cutting method was used. The Lumonics Corporation (Industrial Products Division Office, Livonia, MI) demonstrated that the tank could be cut open using a commercial continuous wave (CW) Nd:YAG laser. The CW laser beam was delivered to the tank by optical fibers positioned by a robotic arm under computer control. A videotape of this operation if available at the ICPP. The preparation steps converted the complex tank into a right circular cylinder that was 40 inches long and 24 inches in diameter with a wall thickness of 0.375 inches.

The Ames Laboratory Engineering Services Department developed an engineering design for the simulated decontamination of the WINCO tank. The design was subject to a major constraint: the assumption that the tank was located in a difficult-to-access environment typical of a hot cell or process cell. The excimer laser and computer used to control the rastering of material through the laser beam were located in a "clean" environment outside of a room that contained the "hot" materials needing decontamination. The excimer laser beam was sent through a port in the wall between the hot area and the clean laser facility (Figure 2). Once in the hot area, the laser beam was directed to the material requiring treatment by a mirror or combination of mirrors. The beam was focused onto the material using a simple lens and material ablated from the metal's surface was routed to a HEPA filter for collection. 


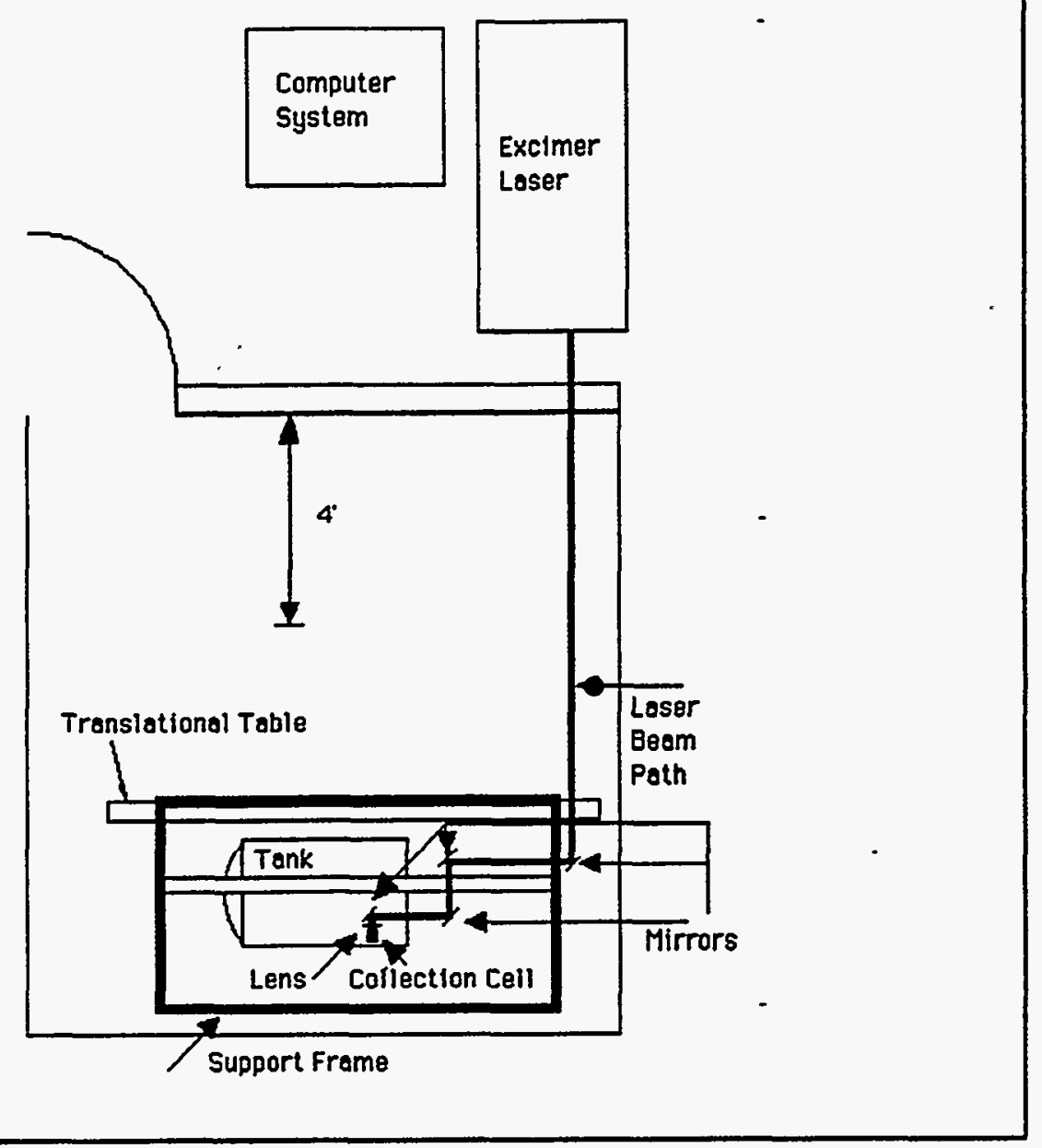

Figure 2, Diagram of Equipment to Simulate Decon of Tank in Restricted Access Area.

The resulting design was based upon the use of a frame constructed over the tank to provide support for translational stages needed to move laser focusing mirrors along the long tank axis. This type of frame does not touch the tank and adjusts to fit objects of different sizes. However, to reduce costs, the frame used for the Ames demonstration was fixed in size and was not surface treated. The laser beam was focused onto the tank surface with a cylindrical lens fitted into a material collection cell (see Figure 1).

The work was done in air at normal pressures to simplify apparatus design and implementation for "real-world" conditions. The Ames apparatus used a photodetector to capture laser light reflected from the surface and automatically adjust the distance between the lens and the surface to maximize ablation efficiency. For the best operation, the direction of the laser beam needs to be perpendicular to the surface being ablated. A rotational stage under computer control to maintain perpendicularity 
seconds of $\mathrm{CO}_{2}$ laser irradiation at $310 \mathrm{~W}$, it was found that about $130 \mu \mathrm{g}$ material per second was vaporized.

The metal samples were deformed as a result of laser irradiation. After the material absorbed the $\mathrm{CO}_{2}$ laser energy, most of this energy heated up the metal piece. As a result, the metal softened and sagged downward. The results indicated that on each traverse of the beam the material was being melted and splattered on both sides of the laser affected zone to produce peaks. A similar pattern was observed when scanning electron microscope (SEM) photographs were taken of the sample. Higher laser power caused more deformation, even with $1 / 8^{\text {" }}$ thick stainless steel plates. A commercial firm that uses $\mathrm{CO}_{2}$ lasers for cutting and welding and advertises the successful use of $\mathrm{CO}_{2}$ lasers for "marking" was contacted and invited to work on some of our samples. They responded that, in their view, it was not possible to remove surface materials with a $\mathrm{CO}_{2}$ laser (even one that could be pulsed on the millisecond time scale) without significant melting. Melting could cause a serious problem by driving surface contaminants below the surface.

Two SIMCON I coupons were ablated using the $\mathrm{CO}_{2}$ laser in an air environment for about 20 seconds. The laser beam was focused onto the surface with a $127 \mathrm{~mm}$ focal length lens. A scanning speed of 400 inches per minute was used. The coupons were analyzed by X-ray fluorescence (XRF) spectroscopy to determine the cleaning efficiency. The results are listed in Table 1.

Table 1, X-ray Fluorescence Analysis of $\mathrm{CO}_{2}$ Laser Cleaned WINCO SIMCON 1 Samples.

\begin{tabular}{|c|c|c|c|c|c|}
\hline Sample & \% removal Zr & \% removal Cs & DF Zr & DF Cs & Laser Power \\
\hline A-11 & 79.0 & 98 & 4.8 & 49.8 & 400 \\
\hline A-12 & 92.2 & 96.3 & 12.9 & 27.3 & 420 \\
\hline
\end{tabular}

These results were better than anticipated. However, it was not known whether XRF analysis can provide a real indication of the effectiveness of $\mathrm{cW} \mathrm{CO}_{2}$ laser cleaning. If, refractory contaminants were driven into the molten metal, a surface sensitive analytical technique, such as XRF, will no longer detect the analytes.

\subsection{Nd:YAG Laser Testing}

Different metal alloys were positioned at the focal plane of the focused Nd:YAG laser beam for the weight change measurement experiment. The sample was moved back and forth $5 \mathrm{~mm}$ along the short axis of the focal plane at a speed of $0.5 \mathrm{~mm} / \mathrm{s}$. Samples were weighed before and after one hour of laser processing. All metals, 
between the laser beam direction and the surface being treated is needed. This was not available at Ames. Thus the tank was "decontaminated" in sections; manually readjusting the tilt of the focusing lens between sections to maintain perpendicularity. These manual adjustments would be very difficult in a process cell.

Characterization of the laser ablation off-gas was performed by sampling the exhaust line and trapping the constituents. In one test, a liquid nitrogen trap was placed before the HEPA filter and air was drawn through it at a rate of 10 to $20 \mathrm{cfm}$. During this test, Monel metal was used as the target. Monel contains roughly $65 \%$ nickel and $35 \%$ copper. These constituents are of particular interest as nickel can form a toxic (nickel carbonyl) compound on heating. The Nd:YAG laser was operated at $30 \mathrm{~Hz}$. for ten minutes. The contents of the trap were rinsed to a $100 \mathrm{ml}$ volumetric flask using $1 \%$ nitric acid and analyzed by ICP-AES. A second test used the same trap system placed behind the HEPA filter. The third test used nickel carbonyl Drager tubes, commercially available for this purpose. The Drager tube was placed in the exhaust line and 2 liters of gas was passed through it during the Nd:YAG laser operation. Sampling times were extended to 45 minutes, or about 21 liters of exhaust gas as a final test.

A final test used a carbopack organic analysis trap to retain the off gas products of PCB contaminated materials for final analysis. The trap was positioned $6 \mathrm{~cm}$ from the exhaust cell and gas drawn through it at a rate of 20-22 $\mathrm{ml}$ per minute to collect 135 to $150 \mathrm{ml}$. Both the Nd:YAG laser and the Krf excimer lasers were used for these tests. The Nd:YAG was operated at $1064 \mathrm{~nm}, 30 \mathrm{~Hz}$., and $170 \mathrm{mj}$ per pulse. The excimer laser was operated at $248 \mathrm{~nm}, 120 \mathrm{~Hz}$., and $330 \mathrm{mj}$ per pulse. Test solutions consisted of: a blank, 2,4,6-trichlorobiphenyl, transformer oil, and arochlor 1016 in transformer oil. These sorbant traps were sent to WINCO for analysis by gas chromatography/mass spectrometry, and are currently awaiting analysis.

\subsection{DISCUSSION OF RESULTS}

\subsection{Continuous Wave Carbon Dioxide Laser Testing}

Samples of $1 / 16$ inch thick 2 inch wide and 2 inch long 304 S.S. were placed in the focal plane of the focused laser beam. Laser power was varied from $100 \mathrm{~W}$ to $1000 \mathrm{~W}$ and the material scanning speed was varied between 300 to 400 inches per minute. The most noticeable effect of the laser on the samples was shape distortion and surface oxidation. When the laser interacted with a fresh sample surface, a very intense yellow-orange glow emanated from the interaction zone. However, if a second pass of the laser was made over an area that had been previously exposed to the laser beam, the emanation was less intense than was originally observed. By measuring the weight lost by the 304 S.S. sample after 170 
except aluminum, turned black after the surface treatment due, presumably, to extensive oxide formation. The results are summarized in Table 2. The weight measurement had a large error due to the difficulty of measuring a small weight change $(10-30 \mathrm{mg})$ in a heavy object $(20-170 \mathrm{~g})$ and the oxide formation on the surface.

Table 2, Measured Weight Loss (ng/pulse) Caused by a Q-switched Nd:YAG Laser.

\begin{tabular}{|l|c|c|}
\hline Metal & $\begin{array}{c}100 \mathrm{~mm} \text { f.l. } \\
\text { cylindrical lens }\end{array}$ & $\begin{array}{c}100 \mathrm{~mm} \text { f.I. } \\
\text { cylindrical lens }\end{array}$ \\
\hline Aluminum & 51 & 51 \\
\hline Copper & 88 & 69 \\
\hline Monel & 64 & 73 \\
\hline 304 S.S. & 50 & 74 \\
\hline 316 S.S. & 49 & 51 \\
\hline Inconel 600 & 55 & 43 \\
\hline Inconel 825 & 56 & 51 \\
\hline Hastalloy $X$ & 52 & 59 \\
\hline Hastalloy C4 & 71 & 59 \\
\hline Hastalloy C22 & 105 & 57 \\
\hline
\end{tabular}

Table 2 demonstrates that the ablation rate was similar for many different alloys. This may be related to the short pulse width of the Nd:YAG laser. At an 8 ns pulse width, the power density of the laser beam on the target was very high $\left(>10^{9} \mathrm{~W} / \mathrm{cm}^{2}\right)$ and a shock wave was created. ${ }^{9}$ This shock wave removed surface material regardless of the melting point of the material. The slight ablation rate difference among alloys then, could be due to differences of photon absorption efficiency and errors in the weight measurement.

In general, when a longer focal length lens is used, a lower power density will be obtained. For example, using a $100 \mathrm{~mm}$ f.l. lens to focus a laser should result in twice the power density resulting from focusing with a $200 \mathrm{~mm}$ f.l. lens. However, in contrast to results obtained with an excimer laser, no significant difference of material removal (with the exception of Hastalloy C22) was observed when these two different focal length lenses were used with the Nd:YAG laser (see Table 2). This may be because the power densities obtained by using both 
lenses have already exceeded the threshold that causes serious gas breakdown so that only a fraction of the energy can reach the material surface.

SIMCON I and SIMCON II coupons were used to measure Nd:YAG decontamination efficiency. The diameter of the coupon $(2.5 \mathrm{~cm})$ was larger than the length of the focused laser beam $(1 \mathrm{~cm})$. Since only one translational table was used, the coupon area was divided into three sections and each section was irradiated by the laser beam for a specified time. The results are summarized in Table 3.

Table 3, X-ray Fluorescence Analysis of the Nd:YAG Laser Cleaned WINCO SIMCON I and SIMCON II Samples.

\begin{tabular}{|c|c|c|c|c|c|c|}
\hline Sample & $\%$ removal Zr & $\%$ removal Cs & DF Zr & DF Cs & passes" & $\begin{array}{c}\text { total time } \\
\text { (sec) }\end{array}$ \\
\hline SIMCON I & & & & & & \\
\hline A-27 & 99.7 & 93.6 & 306 & 157 & 1 & 15 \\
\hline A-28 & 99.8 & 98.7 & 465 & 77 & 1 & 19 \\
\hline A-20 & 100 & 98.8 & $\infty$ & 81 & 2 & 38 \\
\hline A-21 & 100 & 99.4 & $\infty$ & 16 & 2 & 66 \\
\hline A-15 & 100 & 99.8 & $\infty$ & 41 & 4 & 132 \\
\hline A-26 & 100 & 99.7 & $\infty$ & 36 & 6 & 190 \\
\hline A-22 & 99.6 & 99.4 & 236 & 16 & 8 & 264 \\
\hline SIMCON II & & & & & & \\
\hline I-24 & 100 & 73.3 & $\infty$ & 3.7 & 4 & 153 \\
\hline I-19 & 99.5 & 67.2 & 212 & 3.0 & 6 & 229 \\
\hline I-25 & 97.8 & 80.5 & 46.5 & 5.1 & 8 & 305 \\
\hline I-21 & 100 & 79.4 & $\infty$ & 4.9 & 10 & 381 \\
\hline
\end{tabular}

"Each pass represents the one directional movement of the sample.

For SIMCON I coupons, the sample was moved at $2.3 \mathrm{~mm} / \mathrm{s}$. For SIMCON II coupons, the sample was moved at $2.0 \mathrm{~mm} / \mathrm{s}$. 
The results indicate that the laser effectively cleaned the SIMCON I samples, the results were less satisfactory for the SIMCON II samples. Ideally, the SIMCON I surface coating had a minimum thickness of $1.3 \mu \mathrm{m}$ and $5.2 \mu \mathrm{m}$ for the cesium and zirconium salts, respectively; assuming the salts were distributed evenly over the entire surface and retained their chemical compositions after drying. However, there were locally concentrated coatings on the surfaces and the coating was fairly thick (in the order of tens of microns) in certain locations. In addition, no correlation can be observed between the exposure time of laser on the sample and the removal rate. Longer irradiation times did not improve the removal rates. As long as the entire surface was scanned by the Nd:YAG laser, more than $99.6 \% \mathrm{Zr}$ removal (in many cases the removal rates approach $100 \%$ ). The removal rates were slightly lower for Cs but in all cases except sample \#A-27, the removal rates for Cs were about $99 \%$. For SIMCON II samples, the removal rates for $\mathrm{Zr}$ were very similar to the rates obtained for SIMCON I samples but the removal rates for Cs were much lower. The reasons for these differences are not known. It may be because when SIMCON II samples were prepared in a high temperature environment $\left(700^{\circ} \mathrm{C}\right)$, Cs was driven deeper into the stainless steel surface, making it was more difficult to remove.

To test the free running phase of the Nd:YAG laser, samples of 304 stainless steel were placed in the focal point of the laser beam (spherical lens) and moved at a speed of $5 \mathrm{~mm} / \mathrm{s}$. When the laser beam irradiated the sample surface, flying molten metal particles were produced and orange-yellow emissions were observed. Recondensation of melted material was observed at locations adjacent to the laser beam surface interaction zone. The collection cell window, located 9 $\mathrm{cm}$ away from the surface, was coated with molten particles of between 0.1 to $0.5 \mathrm{~mm}$ diameter. This evidence confirmed publication references that suggest that surface melting results from the irradiation of a metal surface by a free running mode Nd:YAG laser. ${ }^{10,11}$ Once liquid metal was formed, it continued to absorb energy and generated high pressure vapor. Then the molten metal was ejected from the surface. In addition, due to the large momentum of the ejected material, it was impossible to capture all the ablated material. When the particle collection cell was located only $2 \mathrm{~mm}$ away from the surface and an air flow of 10 to 20 CFM was used to carry the particles into the cell, a small portion of the ejected material still escaped and redistributed on nearby surfaces. The use of a window to close the top of the cell and contain radioactive particulate was tried, but after a few minutes, the window was coated with ejected material and the transmission of the laser beam was reduced. Also note that using a spherical lens with the Nd:YAG laser reduces the area coverage and results in much longer times to cover large areas. 


\subsection{Excimer Laser Tests}

For comparison with the Nd:YAG laser samples, the same weight measurement method was used for the excimer laser samples. The excimer laser was operated at either $300 \mathrm{~mJ} /$ pulse at $150 \mathrm{~Hz}(45 \mathrm{~W})$ or $350 \mathrm{~mJ} /$ pulse at $120 \mathrm{~Hz}$ $(42.5 \mathrm{~W})$. Metal samples were exposed to the laser beam for 20 minutes. They were translated a distance of $5 \mathrm{~cm}$ back and forth at a speed of $3 \mathrm{~mm} / \mathrm{second}$ during exposure. A $10 \mathrm{~cm}$ uncoated cylindrical lens (18\% energy attenuation) was used to focus the laser beam to a $3 \mathrm{~cm} \times 0.03 \mathrm{~cm}$ line on the sample surface. Experiments were done in air and there was no attempt to prevent oxide formation at the exposed surface. All metals, except aluminum, turned black after the surface treatment. The results are summarized in Table 4. Although at $350 \mathrm{~mJ}$ per pulse output more material was removed, the total amount of material removed at a given time was similar for both energy outputs because the repetition rates were different. At a higher energy output, lower repetition rates were required for the current laser system.

Table 4, Measured Weight Loss (ng/pulse) Caused by Excimer Laser Irradiation.

\begin{tabular}{|l|c|c|}
\hline Metal & $300 \mathrm{mj} /$ pulse & $350 \mathrm{mj} /$ pulse \\
\hline Aluminum & 140 & 149 \\
\hline Copper & 189 & 231 \\
\hline Monel & 151 & 196 \\
\hline 304 S.S. & 53 & 66 \\
\hline 316 S.S. & - & 44 \\
\hline Inconel 600 & 151 & 196 \\
\hline Inconel 825 & 80 & 101 \\
\hline Hastalloy X & - & 66 \\
\hline Hastalloy C4 & - & 83 \\
\hline Hastalloy C22 & - & 117 \\
\hline
\end{tabular}

In general, the excimer laser removed more material than the Nd:YAG laser (compare the results in Tables 2 and 4). Several factors contribute to this. First of all, the excimer laser had an $28 \mathrm{~ns}$ pulse width that was longer than the $8 \mathrm{~ns}$ Nd:YAG laser pulse width. This longer pulse width minimized the gas breakdown and allowed more photons to reach the surface. ${ }^{12}$ Second, the excimer laser wavelength was in the UV, which provided better surface absorption. The 
Nd:YAG laser has an infrared wavelength that has more reflection from the metal surface. Better absorption means higher ablation efficiency. Third, the different ablation efficiency may be caused by the difference of laser energy and power density. The excimer laser provided higher energy output and covered more area than the Nd:YAG laser, but the Nd:YAG laser offers much higher power density. As results of these factors, the excimer laser provides a better removal efficiency on a per pulse basis.

The cylindrical lens focal length was changed on the excimer laser from 100 $\mathrm{mm}$ to $200 \mathrm{~mm}$, to allow a longer of depth of field at the expense of power density. When a longer focal length lens was used, the laser ablation efficiency dropped to $60 \%, 47 \%$, and $29 \%$ for $\mathrm{Cu}$, Monel, and Al. This result was expected since a higher power density should result in better material removal rates. If the power density became high enough to generate a gas phase plasma, the laser energy would be absorbed before reaching the surface as seen in using the Nd:YAG lasers. In certain applications, such as the laser treatment of irregular surfaces, the use of a long focal length lens with a correspondingly longer depth of field may be indicated.

Several SIMCON I and SIMCON II samples were treated by the excimer laser at $350 \mathrm{~mJ}$ per pulse with $150 \mathrm{~Hz}$ for SIMCON I and $120 \mathrm{~Hz}$ for SIMCON II. A speed of $9.3 \mathrm{~mm} / \mathrm{s}$ for SIMCON I and $5.0 \mathrm{~mm} / \mathrm{s}$ for SIMCON II was used to move the samples through the focused laser beam. Because the length of the focused laser beam $(3 \mathrm{~cm})$ was larger than the sample diameter $(2.54 \mathrm{~cm})$, a single pass was sufficient to cover the entire sample. After laser surface cleaning, the samples were analyzed by X-ray fluorescence. The results are summarized in Table 5.

Similar to the Nd:YAG laser results, there was no real correlation between the exposure time and the removal rates measured. There was no significant removal rate difference between more passes and fewer passes as long as the total exposure times were kept the same. For SIMCON I samples, Cs removal rates were slightly better than $\mathrm{Zr}$ removal rates but became much lower in SIMCON II samples.

Radioactively contaminated samples were also cleaned using the excimer laser. The laser was situated so the laser beam was directed through a wall onto radioactive materials in a contamination control area in an adjacent room. The first samples cleaned were aluminum disks cut from ducting used at the Ames Laboratory Alpha Facility. The thorium contaminated metal, and was cleaned at an effective speed of $2 \mathrm{~m}^{2} / \mathrm{hr}$. The coupons were decontaminated to meet Ames Laboratory guidelines for unrestricted release of material, (i.e. no contamination was detected above background levels). 
Table 5, X-ray Fluorescence Analysis of the Excimer Laser Cleaned WINCO SIMCON I and SIMCON II Samples.

\begin{tabular}{|c|c|c|c|c|c|c|}
\hline Sample & \% removal Zr & \% removal Cs & DF Zr & DF Cs & passes" & $\begin{array}{l}\text { total time } \\
\text { (sec) }\end{array}$ \\
\hline SIMCON I & & & & & & \\
\hline A-14 & 97.8 & 99.7 & 46.4 & 305 & 7 & 0 \\
\hline A-16 & 97.4 & 99.6 & 38.2 & 259 & 9 & 26 \\
\hline A-19 & 97.9 & 98.8 & 46.7 & 81.6 & 2 & 34 \\
\hline A-18 & 98.3 & 99.5 & 57 & 194 & 4 & 34 \\
\hline A-17 & 97.2 & 99.1 & 36 & 117 & 4 & 34 \\
\hline A-24"* & 94.0 & 99.8 & 16.8 & 430.4 & 10 & 51 \\
\hline A-29 & 94.8 & 96.6 & 19.1 & 29.5 & 20 & 56 \\
\hline A-23 & 99.1 & 98.7 & 116 & 75 & 2 & 102 \\
\hline A-30 & 99.2 & 100 & 122 & $\infty$ & 20 & 102 \\
\hline A-13 & 99.1 & 99.9 & 108 & 920 & 40 & 203 \\
\hline A-25 & 98.5 & 99.4 & 67 & 174 & 4 & 203 \\
\hline SIMCON II & & & & & & \\
\hline I-29 & 99.7 & 68.9 & 298 & 3.2 & 4 & 20 \\
\hline I-27 & 99.7 & 78.9 & 338 & 4.7 & 6 & 31 \\
\hline I-28 & 99.1 & 79.2 & 113 & 4.8 & 8 & 41 \\
\hline I-26 & 98.1 & 82.6 & 53.9 & 5.7 & 10 & 51 \\
\hline
\end{tabular}

"Each pass represents the one directional movement of the sample.

"A-24 was treated as SIMCON II.

Two additional radioactive tests were performed using ICPP radioactive material designated REALCON 1 and 2. Five nozzles (REALCON 1) from the New Waste Calcining Facility at WINCO were sent for laser decon. These nozzles were used to spray radioactive effluent into the calciner. They had already been chemically decontaminated at the ICPP, but retained residual contamination. These calciner nozzles were made of an extremely hard and durable metal composed largely of cobalt (Stellite 25, Haynes, Co.). Each nozzle had a radiation 
reading of about $3 \mathrm{mr} / \mathrm{hr}$, with a primary constituent of $\mathrm{Co}^{60}$. Laser decon was essentially unsuccessful at cleaning these samples. The radioactive contamination appeared to extend well below the surface of the metal. Surface cracks and fissures may have contributed to the inability of the laser to decontaminate REALCON 1. The results indicate that some underlying radiation was exposed as the laser treatments progressed, The radiation readings increased for the first three passes, decreasing to those of the original metal after about six passes.

REALCON 2 samples were cleaned more successfully with the lasers. REALCON 2 coupons were cut from criticality barriers, used in the fuel storage basins at the FSA building. Criticality barriers were spacers used to separate fuel assemblies in underwater storage racks. Each criticality barrier has had about 5 years use. The samples were 304 stainless steel, cut into approximately 1" squares. Initial readings on each coupon yielded a little less than $1 \mathrm{mr} / \mathrm{hr}$, with the primary gamma emitters of $\mathrm{Cs}^{137}$ and $\mathrm{Co}^{60}$. Data obtained from cleaning the three samples is shown on Figure 3. These samples were considered completely decontaminated.

\subsection{Gas Environment, Lens and Surface Coating Effect on Ablation}

When a short-pulse $(<150 \mathrm{~ns})$ laser is focused on a metal surface, the cover gas environment plays an important role in the transfer of light energy to the surface. Maximum ablation efficiency was obtained when the sample was in a vacuum. ${ }^{13}$ When the gas pressure increases, the efficiency decreases with a complex relationship that depends upon gas properties. In general, when gases are present, lower ablation efficiency was observed due to gas breakdown caused by the high power density of the laser beam at its focal plane location. A highly ionized plasma was formed above the surface that absorbed a large fraction of the laser energy and prevented laser photons from reaching the sample surface. The magnitude of the laser energy loss depended upon the gas pressure, the ionization potential of the cover gas, and the laser power density. At lower gas pressures, the plasma density decreased and more laser photons penetrated the plasma to reach the sample surface. Gases with high ionization potentials, (e.g., He), retarded gas breakdown and prevented the formation of plasma. Thus, atmospheric pressure laser metal ablation rates were greatest when measured in a helium environment. Argon and air have similar ionization potentials and similar ablation efficiencies. In addition, high laser power densities favor the formation of plasmas. 


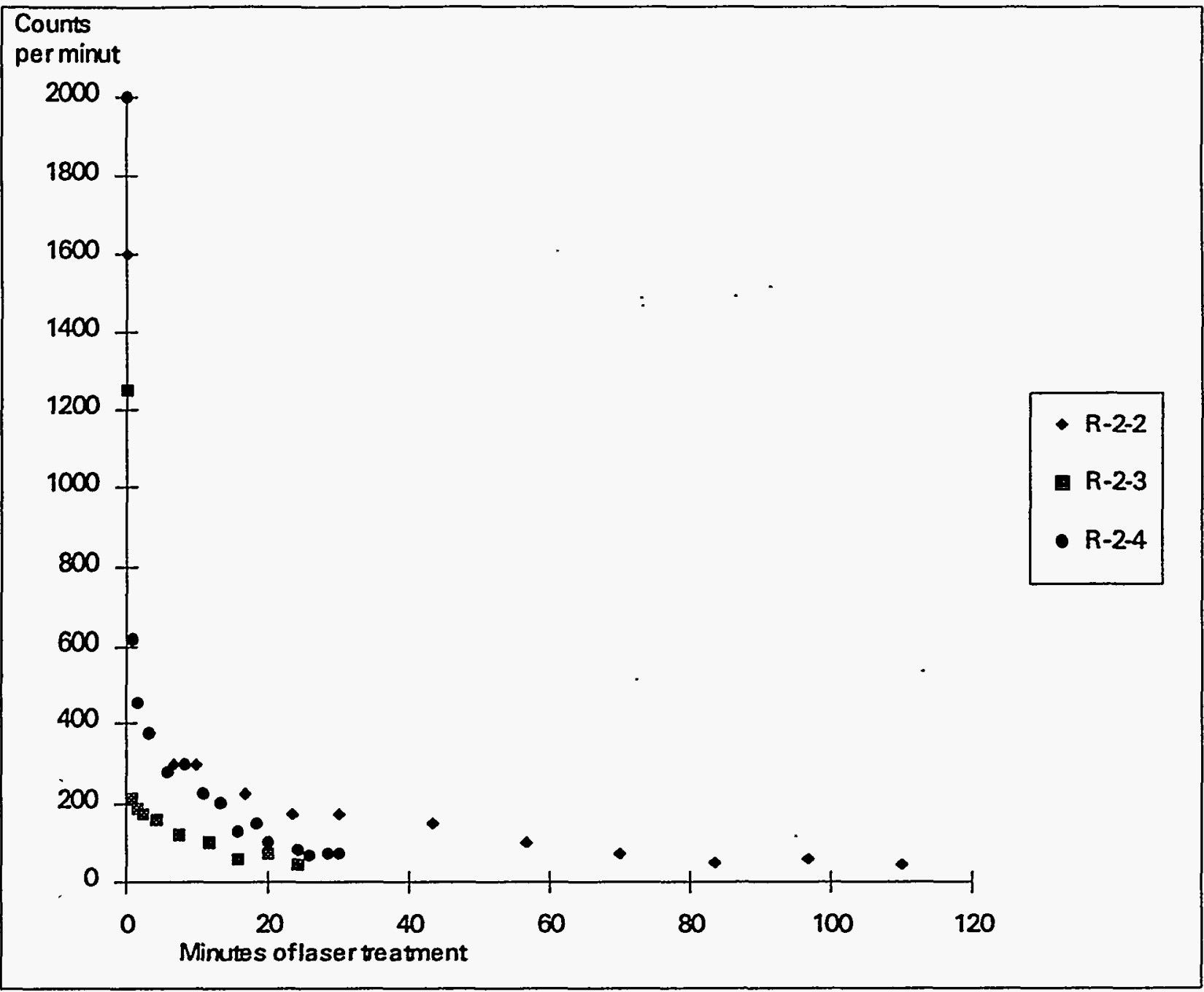

Figure 3, Graph of Total Beta/Gamma Activity Versus Time of Laser Exposure.

As the laser power density at a surface was increased, a point was reached where only a small fraction of the added laser energy reached the material surface. Once this threshold was exceeded, there was little ablation rate improvement with increased laser power density. Because plasma formation is the limiting factor, it was possible to increase ablation efficiency by slightly defocusing a high power density beam to achieve useful power densities over a larger area. Alternatively, a cylindrical lens can be used to lower the power density so that sufficient power was available for efficient ablation without causing, gas breakdown near the surface. The use of a cylindrical lens for focusing provided the additional benefits of large area coverage and easier overlap of laser beams on surfaces. As a result of reduced gas breakdown and larger area coverage, up to $50 \%$ greater ablation 
rates can be obtained using cylindrical lenses, assuming the energy of the laser pulse can be adjusted suitably. All the short pulse lasers tested used a cylindrical lens for focusing.

The focusing conditions for the cylindrical lens were studied using the excimer laser. Scanning electron microscope (SEM) photographs indicated that when the sample surface was located in the focal plane, the material removed from the surface by a laser pulse was maximized. (See the excimer laser section for experimental details.) The focal plane had a $1.0 \mathrm{~mm}$ depth of field for a 100 $\mathrm{mm}$ f.l. cylindrical lens at a wavelength of $248 \mathrm{~nm}$. Material was removed at $95 \%$ of the maximum when the surface was located $0.5 \mathrm{~mm}$ away from the focal plane. Thus, the sample surface can be located within $\pm 0.5 \mathrm{~mm}$ of the focal plane with little loss of laser ablation efficiency. The depth of field is expected to be approximately four times longer at the Nd:YAG laser wavelength $(1064 \mathrm{~nm})$. A long depth of field is particularly useful for ablating material from irregular surfaces. There was a trade off between the depth of field and the power density at a given energy output and wavelength. To obtain long depths of field, longer focal length lenses were required that yield lower power densities that may result in reduced ablation efficiency.

Due to the nature of laser ablation, particles were ejected from the surface during laser surface decontamination. Redeposition of those particles onto adjacent surface areas can seriously reduce the efficiency of laser surface decontamination. The distribution of redeposited material adjacent to the ablation area was examined in an experiment performed in 1992 with DOE EM-50 funding. this experiment was designed to test the effectiveness of two different lens types for laser focusing (both with $100 \mathrm{~mm}$ f.l.). A series of glass slides were positioned on the edge of a copper block and an excimer laser was used to ablate material from a $35 \mathrm{~mm} \times 0.25 \mathrm{~mm}$ area near the edge of the block. For the spherical lens, which had an $248 \mathrm{~nm}$ anti-reflection coating on both surfaces, the copper block was moved at a speed of $3 \mathrm{~mm} / \mathrm{s}$ back and forth to cover the specified area; no rastering was necessary when the cylindrical lens was used since the focused laser beam filled the entire length of the block. After the ablation experiment, the glass slides were washed individually with nitric acid to dissolve any $\mathrm{Cu}$ containing particles. The nitric acid solutions were then analyzed for $\mathrm{Cu}$ by inductively coupled plasma mass spectrometry. A substantial coating, corresponding to $6 \%$ of the material removed during the ablation process, was observed on the first three slides when a spherical lens was used to focus the laser beam. However, less than $0.5 \%$ of the material removed by laser ablation redeposited on the adjacent area when a cylindrical lens was used. Because redeposition cannot be totally eliminated, several passes of the laser beam on the metal surface may be required to totally remove contaminants. 
Laser ablation can remove chemical contaminants and coatings, such as oil and paint, from surfaces. However, the destruction of organic contaminants consumes laser energy and longer exposure times were required to decontaminate coated surfaces. The extra time required depends on the thickness and the characteristic properties of the organic contaminants.

The laser ablation tests of off-gas characterization did not detect contaminants passing through the HEPA filtration system. Tracking of nickel and the formation of toxic nickel carbonyl, was used to determine the extent of toxic gas formation. Tests were developed to trap nickel carbonyl in a nitrogen trap. These tests collected $67 \mathrm{ppb}$ of nickel prior to the HEPA filter, and $<2 \mathrm{ppb}$ after the HEPA filter in approximately 17 cubic meters of air. Less than $24 \mathrm{ng} / \mathrm{m}^{3}$ of nickel was collected downstream of the HEPA filter (based on using the detection limit of the method as an absolute value), or about 5000 times less than the Threshold Limit Value of $0.12 \mathrm{mg} / \mathrm{m}^{3}$ for nickel. The value produced prior to the filter was below the TLV by about 150 times. This indicates little likelihood of toxic gas production given the high quantity of nickel present in the Monel metal. Drager tube test results also produced no discernable indication of nickel carbonyl. A second series of tests, to determine if PCB contaminated material was cleaned without generating hazardous materials, were conducted using organic sorbant traps. These traps have not been analyzed through the gas chromatograph/mass spectrometer. Results are expected within a few months. Surveys of the off-gas

equipment for radioactivity subsequent to REALCON tests detected no radioactive contamination beyond the HEPA filter.

\subsection{Application of Light Ablation to Hot Cell Equipment}

The study of the mobility/application of lasers to in-cell decontamination occurred in three phases. Phase one examined mobile lasers, phase two focused on the transmission of light through fiber optics and phase three looked at moving mirrors in the cell with the laser in a clean environment. The mobile laser phase used information gathered from the Nd:YAG laser tests to develop a conceptual design for the Mobile Light Ablation Decontamination Device (MLADD). Remote head, Q-switched lasers are commercially available and can be mounted to robotics devices for delivery of the light into a cell environment. Two manufacturers, Big Sky Lasers of Bozeman, Montana, and Photonics, Inc. of Orlando, Florida, have this type of remote head laser. The laser head typically weighs about 40 pounds and can be removed up to one hundred feet from the power supply. These units are capable of producing about $50 \mathrm{mj}$ of power at 30 $\mathrm{Hz}$. This would be acceptable for flat surfaces, such as walls and floors, and might be adaptable for tanks and some pipes. A Commerce Business Daily announcement sought commercial partners for developing the MLADD. Fifteen 
different companies responded to the announcement and request for proposal. However, this work is on hold due to limited funding.

The second phase of the mobility study, using fiber optics to position the laser light in the hot cell, is a better though more difficult approach. A fiber optically coupled laser would allow the expensive laser head and electronics to remain completely isolated from the hot cell environment. It would also allow laser flexibility to do several different kinds of jobs (not only flat work). Lasers having a wavelength above $300 \mathrm{~nm}$ are acceptable for fiber optic coupling, which allows the Nd:YAG and prohibits the KrF excimer from serious fiber optic consideration. Passing electro-optic Q-switched laser light through a fiber optic required significant development. Q-switching lasers tends to dramatically increase the power density of the laser (up to $1 \times 10^{9}$ watts $/ \mathrm{cm}^{2}$ ), which damages fibers that are designed primarily for non-Q-switched applications. Research was performed on different kinds of fibers, polishing methods and holders. However, even with considerable effort, breakdown of the $3 \mathrm{M}$ fiber occurred typically at less than 40 $\mathrm{mj} /$ pulse; which was far less than the $190 \mathrm{mj}$ capability of the Nd:YAG laser.

Phase three focused on the production scale application of laser decontamination to a stainless steel WINCO tank. An uncontaminated WINCO tank was used for this demonstration. The use of a laser apparatus for the in situ decontamination of this tank was demonstrated by removing a layer of black paint from the outer surface and grease from the inner surface of the tank (Figure 4 and 5). The demonstration was conducted with the tank resting on the floor the way it would in a process environment. The tank cleaning demonstrated that the laser could reach virtually the entire tank surface, both internal and external. The laser could not reach a small portion of the two supports used to balance the tank on the floor. 


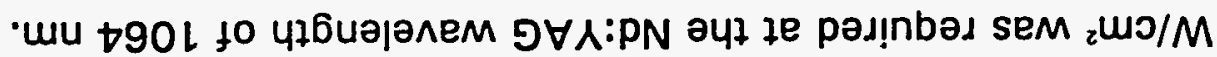

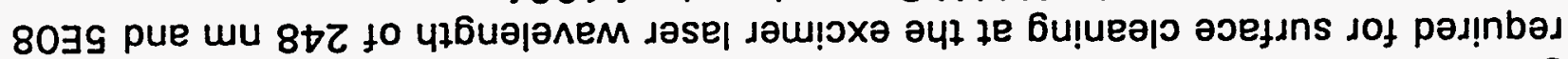

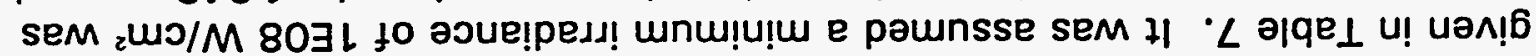

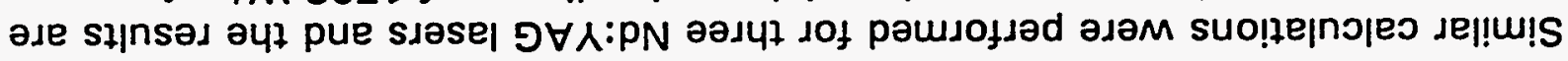

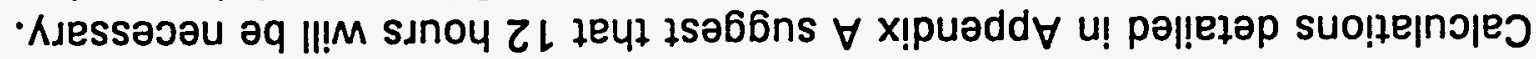

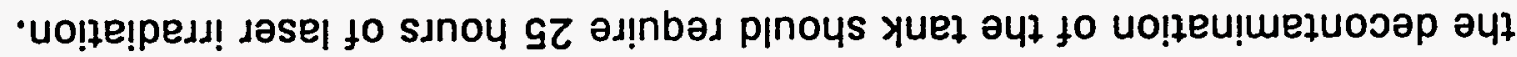

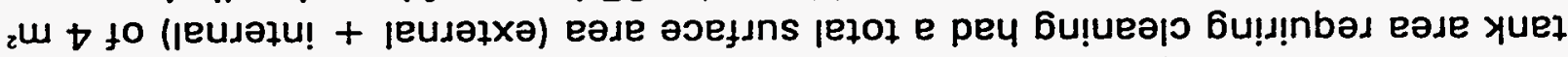

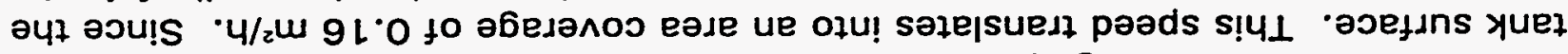

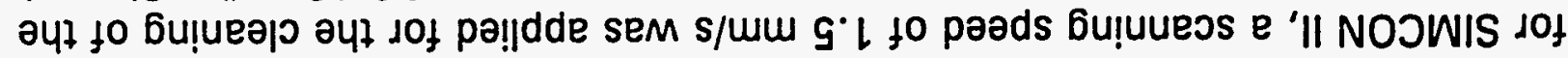

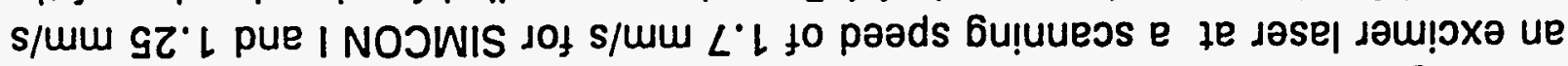

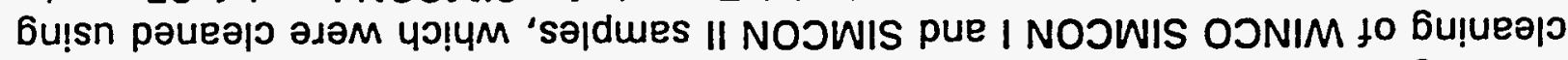

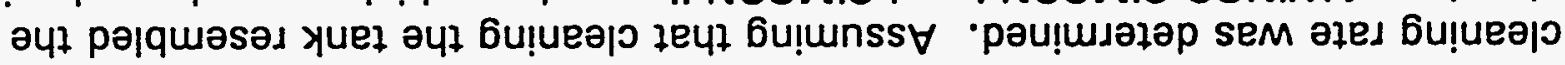

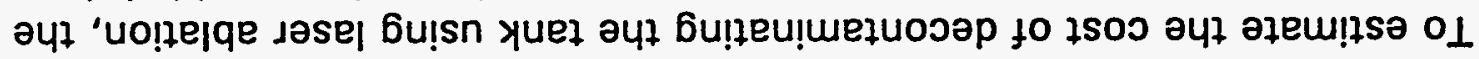

'jenoway zu!

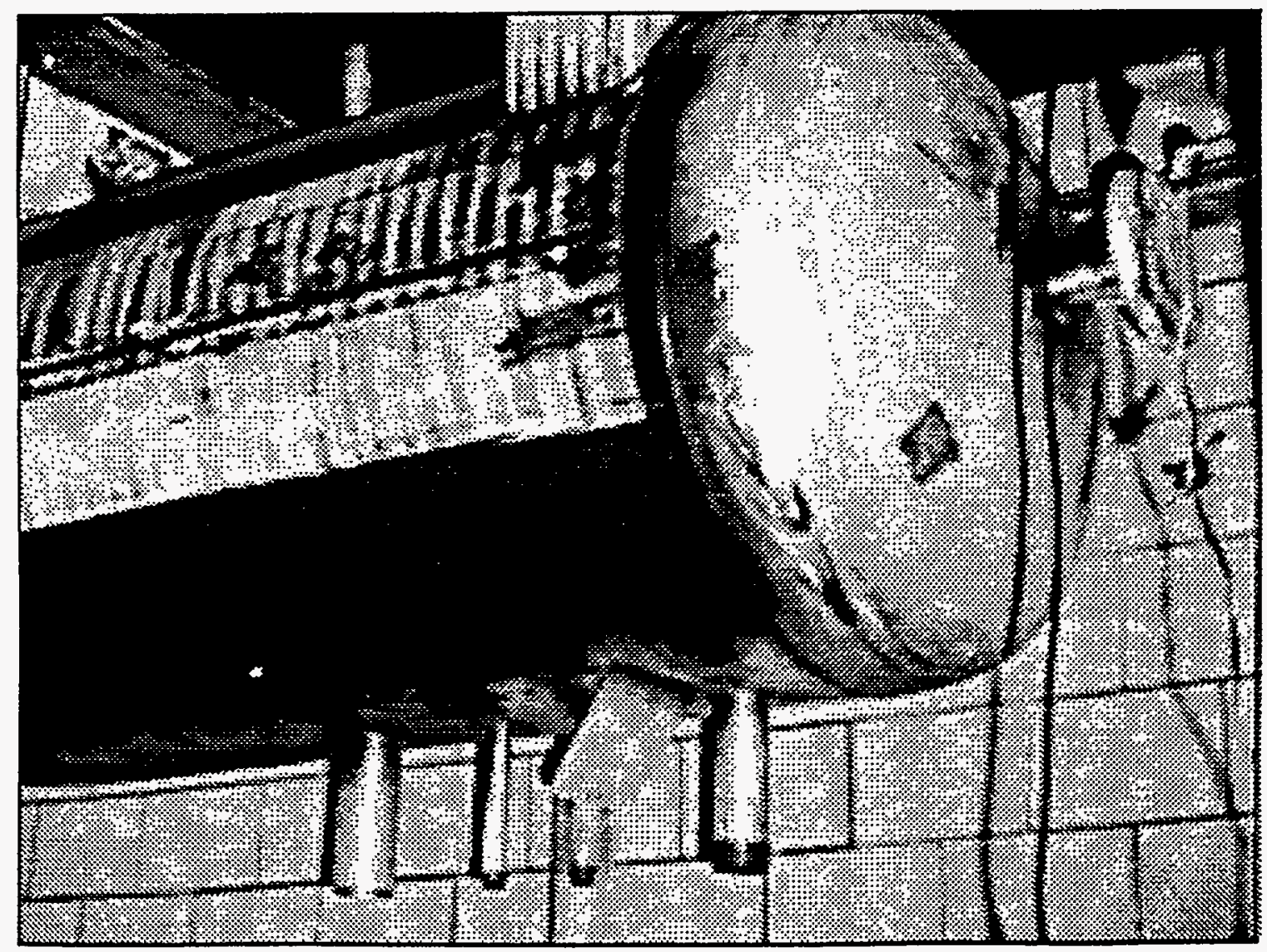




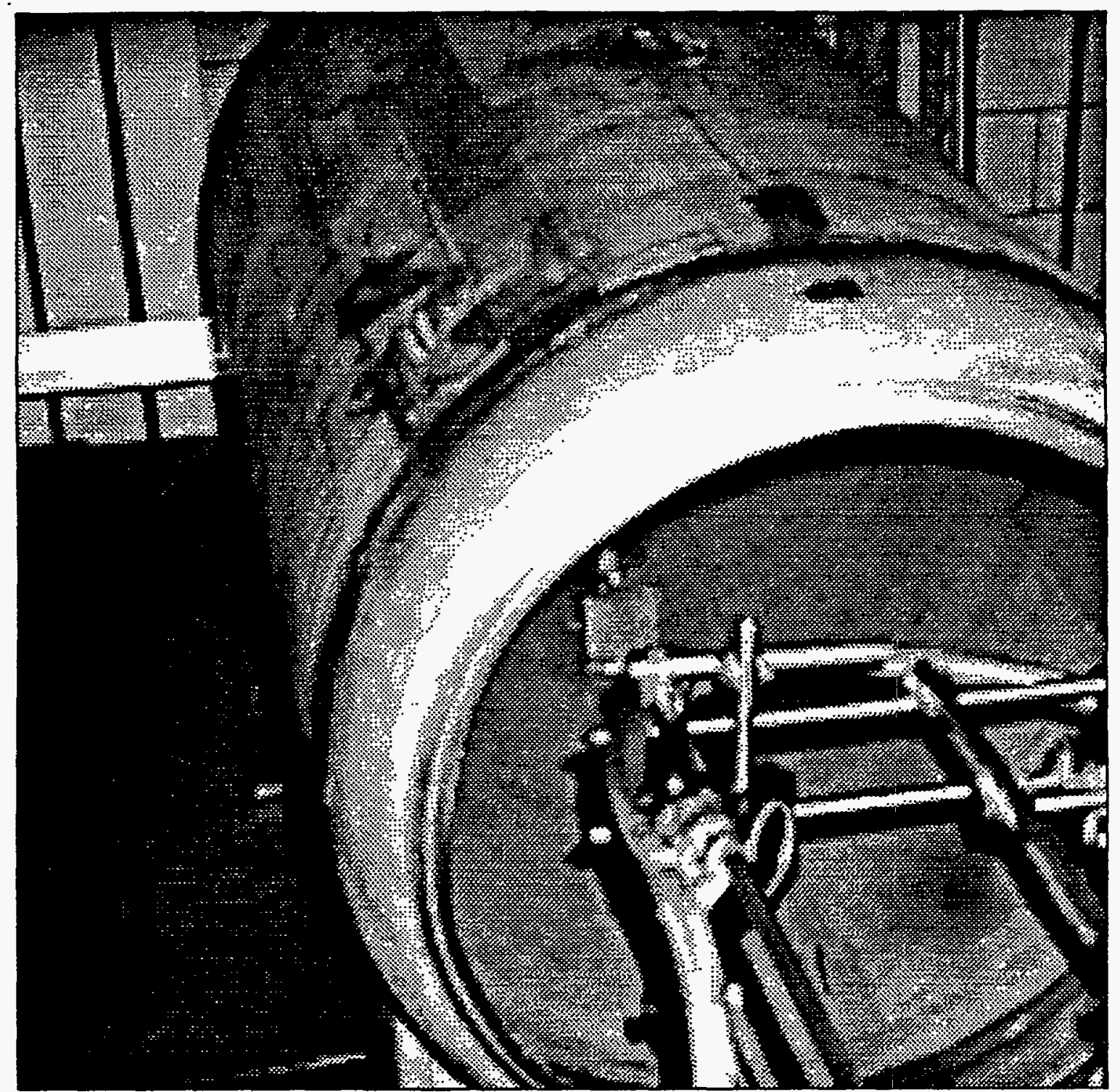

Figure 5, Photograph of Optics and Cell Deployed in Tank Interior.

To minimize maintenance requirements, the Ames group used its excimer laser at roughly $50 \%$ of rated power. The calculations used to compute the excimer laser result in Table 6 assumed the use of the excimer laser at roughly $50 \%$ of rated average power. Values for Nd:YAG parameters were chosen at roughly $100 \%$ of rated output power. An excimer laser with an average power in excess of $1000 \mathrm{~W}$ is commercially available (SOPRA VEL 1) and another with an average power of roughly $2000 \mathrm{~W}$ is under development in Japan. Assuming conservative operation of these devices (50\% of maximum power operation), it was likely that the 12 hour cleaning time could be reduced substantially. It isn't clear that cost savings would result from the application of very high pulse power 
lasers to small cleaning projects. However, cleaning certain large projects (e.g., large walls) may be cost effective with the large laser systems.

Table 6, Relevant Parameters and Estimated Time Required to Decontaminate WINCO Tank Using Excimer and Nd:YAG Lasers*.

\begin{tabular}{|l|l|l|l|l|}
\hline Laser & $\begin{array}{l}\text { Excimer } \\
\text { [Questek 2460 vB] }\end{array}$ & $\begin{array}{l}\text { Nd:YAG } \\
\text { [Continuum } \\
\text { YG660] }\end{array}$ & $\begin{array}{l}\text { Nd:YAG } \\
\text { [Continuum NY82] }\end{array}$ & $\begin{array}{l}\text { Nd:YAG } \\
\text { [US Laser] }\end{array}$ \\
\hline Rep. Rate & $150 \mathrm{~Hz}$ & $30 \mathrm{~Hz}$ & $30 \mathrm{~Hz}$ & $5000 \mathrm{~Hz}$ \\
\hline Pulse Energy & $250 \mathrm{~mJ}$ & $150 \mathrm{~mJ}$ & $70 \mathrm{~mJ}$ & $50 \mathrm{~mJ}$ \\
\hline Pulse Width & $25 \mathrm{~ns}$ & $8 \mathrm{~ns}$ & $10 \mathrm{~ns}$ & $150 \mathrm{~ns}$ \\
\hline Focused Area & $0.1 \mathrm{~cm}^{2}$ & $0.037 \mathrm{~cm}^{2}$ & $0.14 \mathrm{~cm}^{2}$ & $6.7 \mathrm{E}-4 \mathrm{~cm}^{2}$ \\
\hline Pulses/Area & 15 & 15 & 15 & 15 \\
\hline Time & $11.4 \mathrm{hrs}$ & $151.4 \mathrm{hrs}$ & $40.5 \mathrm{hrs}$ & $51.1 \mathrm{hrs}$ \\
\hline
\end{tabular}

Calculations based on $1 \mathrm{E} 08 \mathrm{~W} / \mathrm{cm}^{2}$ irradiance for excimer laser decontamination and 5E08 $\mathrm{W} / \mathrm{cm}^{2}$ for $\mathrm{Nd}$ :YAG lasers (Appendix A).

The cost for tank cleaning was estimated using estimated yearly operating costs. The annual cost figures were prorated against the estimated tank cleaning time. Additional labor costs during experimental set-up were added. For the cost estimate it was assumed the laser was operated for 3000 hours/year. This time was prorated against the time to clean the tank to obtain the cost of laser operation (Tables 7-9, capital equipment, maintenance and supplies). The laser operator was assumed to spend seven hours setting up the tank cleaning and an additional three hours observing the work in progress and dismantling at the job conclusion. The operators time (10 hours, 5 times the Ames setup time) was compared against a 2000 hour annual work effort ( 40 hours/week $X 50$ weeks/year) to arrive at the percentages in Tables 8-10. Costs were also included for a worker to assist in setting up the frame and aligning the laser $(6$ hours at $\$ 50 /$ hour). Note that labor costs could be substantially reduced if the laser operator were responsible for more than one laser decontamination apparatus, assuming a high degree of computerized operation. A major uncertainty in the calculation of Nd:YAG laser costs is the cost of the optical fibers. These should be added, when known, to the supplies portion of the tables. The cost of installing an optical access port into a hot cell was also omitted. The lasers used for this comparison were not representative of the current commercial state-of-theart therefore these costs are conservative. The estimated costs do not include costs for engineering diagram preparation, safety studies, and dismantlement 
procedures needed prior to decontamination. Appendix B gives detailed information on the cost estimate data used in Tables 7-9.

Table 7, Estimate Tank of Decontamination Costs (Excimer Laser).

\begin{tabular}{|l|l|l|l|}
\hline OPERATION & ANNUAL COST & DUTY FACTOR $(\%)$ & ESTIMATED COST \\
\hline Laser operator & $\$ 100,000$ & 0.5 & $\$ 500$ \\
\hline Capital equip. & $\$ 17,500$ & 1 & $\$ 175$ \\
\hline Maintenance & $\$ 5,000$ & 1 & $\$ 50$ \\
\hline Supplies & $\$ 9,000$ & 1 & $\$ 90$ \\
\hline Set-up labor & N/A & 100 & $\$ 300$ \\
\hline Contingency & & 25 & $\$ 325$ \\
\hline Total Cost & & & $\$ 1350$ \\
\hline
\end{tabular}

Table 8, Estimate Tank of Decontamination Costs (Continuum YG660).

\begin{tabular}{|l|l|l|l|}
\hline \multicolumn{1}{|c|}{ OPERATION } & ANNUAL COST & DUTY FACTOR $(\%)$ & ESTIMATED COST \\
\hline Laser operator & $\$ 100,000$ & 0.5 & $\$ 500$ \\
\hline Capital equip. & $\$ 10,925$ & 5 & $\$ 546$ \\
\hline Maintenance & $\$ 2,900$ & 5 & $\$ 145$ \\
\hline Supplies & N/A & - & $\$ 0$ \\
\hline Set-up labor & N/A & 100 & $\$ 300$ \\
\hline Contingency & & 25 & $\$ 373$ \\
\hline Total Cost & & & $\$ 1864$ \\
\hline
\end{tabular}


Table 9, Estimate Tank of Decontamination Costs (Continuum NY82).

\begin{tabular}{|l|l|l|l|}
\hline \multicolumn{1}{|c|}{ OPERATION } & ANNUAL COST & DUTY FACTOR $(\%)$ & ESTIMATED COST \\
\hline Laser operator & $\$ 100,000$ & 0.5 & $\$ 500$ \\
\hline Capital equip. & $\$ 17,375$ & 1 & $\$ 174$ \\
\hline Maintenance & $\$ 6,800$ & 1 & $\$ 68$ \\
\hline Supplies & N/A & - & $\$ 0$ \\
\hline Set-up labor & N/A & 100 & $\$ 300$ \\
\hline Contingency & & 25 & $\$ 260$ \\
\hline Total Cost & & & $\$ 1302$ \\
\hline
\end{tabular}

\subsection{SUMMARY OF RESULTS}

The study of laser decontamination has demonstrated that it is a viable decontamination method. Three different kinds of lasers were used to clean SIMCON I and SIMCON II coupons with good to excellent results. In addition, two of the three radioactively contaminated metal samples were decontaminated to below typical background levels. The real benefit, though, is gained from the absence of secondary waste.

It was difficult to compare the performance between the Q-switched $\mathrm{Nd}$ :YAG laser and the excimer laser for the surface decontamination because the operating conditions (energy output, pulsed width, and beam profile) were not the same. The efficiency cited in this report was based on the current laser systems available at Ames and can be improved substantially by using a higher power laser. Comparing the results in Table 3 and Table 6 shows that there is no significant difference in SIMCON I and SIMCON II removal rates between the Qswitched Nd:YAG laser and the excimer laser.

The advantage of using Q-switched Nd:YAG lasers is the possibility of using optical fiber to carry the laser beam. Nd:YAG lasers are more mature than the excimer laser based on the ease of use and maintenance, and reliability. In addition, a compact Nd:YAG laser can be produced with sacrificing power output. The compact laser may be useful for small surface area decontamination.

The use of an excimer laser can provide a better cleaning efficiency in unit time because excimer lasers provide higher repetition rates and higher average power output than Nd:YAG lasers. In addition, due to the flat top energy distribution, the cleaning efficiency was fairly even throughout the entire laser 
beam. A big disadvantage of using an excimer laser was the use of hazardous halogen gas that requires strict gas-handling and safety controls. However, a new development for excimer lasers may overcome this problem. Lambda Physik (the largest excimer laser vender) has developed a system that uses two non-toxic compounds to react and produce high-purity fluorine and hydrogen chloride gas inside the laser head. This internal halogen-gas generator eliminates the need for most external gas tanks, safety housing, and ventilation equipment.

\subsection{RECOMMENDATION}

Light ablation decontamination is a viable decontamination tool which requires further development of handling equipment for application of laser decontamination to typical hot-cell environments. The use of the excimer to clean the large tank demonstrated that laser systems can be adapted to ICPP equipment. However, practical, uncomplicated beam delivery systems need to be developed to accomplish the task. This development work is ongoing through additional contract work.

\subsection{REFERENCES}

${ }^{1}$ Ansley, D., "Have Laser, Will Travel," Discover, December 1990.

${ }^{2}$ Forest, Gary T., "Nd:YAG Lasers Strip Paint Effectively," Industrial Laser Review, December 1992.

${ }^{3}$ Foley, J. S., "Laser Paint Stripping: An Automated Solution," IndustrialLaser Review, Vol. 6, No. 3, July 1991.

${ }^{4}$ Demmer, R. L., "Report on the Decontamination Techniques Examined in FY 1993", Letter RLD-06-93, May 1993.

${ }^{5}$ Flesher, D, J,. "Light Aided (LASER) Decontamination", WHC-SD-WM-TI-518, July 1992.

${ }^{6}$ Pang, H-M., et al, "Laser Decontamination: A New Strategy for Facility Decommission," Proceedings 1992 Int. Topical Meeting on Nuclear and Hazardous Waste Management, August 1992.

${ }^{7}$ Pang, H-M, et al, "Metal Decontamination Using High Power Lasers", ER'93 Environmental Remediation Conference, October 1993.

${ }^{8}$ Demmer, R. L., "Development of Simulated Contamination (SIMCON) And Miscellaneous Scoping Tests", WINCO-1188, January 1994. 
9 Piepmeier, E. H., et al, "Atmospheric Influences on Q-switched Laser Sampling and Resulting Plumes", Applied Spectroscopy, Vol. 25, No. 6, 1971.

${ }^{10}$ Cingolani, A., et al, "Metal Drilling Investigation by Means of Different High Power Laser Radiation", Applied_Physics Communication, Vol. 2 (1-2), 1982.

$"$ Ready, J. F., "Effects of High-Power Laser Radiation", Academic Press, 1971.

${ }^{12}$ Briand, A., et al, "Optical Spectroscopic Instrumentation and Techniques for the 1990s", SPIE, Vol. 1318.

${ }^{13}$ Lida, Y., "Effects of Atmosphere on Laser Vaporization and Excitation Processes of Solid Samples", Spectrochim. Acta, Vol 45B, 1990. 
APPENDIX A

Calculation of Decontamination Times 


\section{Calculation of Decontamination Times for Excimer and Nd:YAG Lasers}

We presume that there is a minimum irradiance $\left(I_{\min }\right)$ required to ablate material from a metal surface. This value should be material specific. Walters ${ }^{8}$ indicated that $2.7 \mathrm{~J} / \mathrm{cm}^{2}$ is required to "damage" the surface of 316 SS using an laser operating at $266 \mathrm{~nm}$. This "fluence" value, when converted to an "irradiance" value by dividing by Walter's pulse width $(-20 \mathrm{~ns})$ is approximately $-1 E 08$ watts $/ \mathrm{cm}^{2}$. Results obtained in our laboratory demonstrated that surface decontamination efficiency increased markedly as the irradiance is increased above $I_{\min }$. These results are shown in Fig $A 1$.

The variation in loss of radioactive contamination, shown in Figure $A 1$, with irradiance appears to be roughly linear.

A recent paper ${ }^{9}$ contained evidence that ultraviolet laser pulses are considerably more effective in ablating material from metals than visible or infrared laser pulses. The authors reported that:

In Fig. 2 [reproduced below as Fig. A2], it is shown that the ablation efficiency, (ablated mass per unit energy per unit surface) as a function of laser fluence is more than one order of magnitude higher (20 times) for a UV laser than for an IR laser or even a visible laser at $200 \mathrm{~J} \mathrm{~cm}^{-2}$.

${ }^{8}$ C.T. Walters, "Short Wavelength/Surface Interaction in Vacuum," Paper AIAA-81-1154, Proceedings of the AIAA 16th Thermophysics Conference, Palo Alto, CA (June 23-25, 1981).

${ }^{9}$ C. Geertsen, A. Briand, F. Chartier, J-L. Lacur, P. Mauchien, S. Sjostrom, and J-M. Mermet, "Comparison Between Infrared and Ultraviolet Laser Ablation at Atmospheric Pressure - Implications for Solid Sampling Inductively Coupled Plasma Spectrometry," J. Anal. Atomic Spectrom., 9 (1994) 17 - 22. 


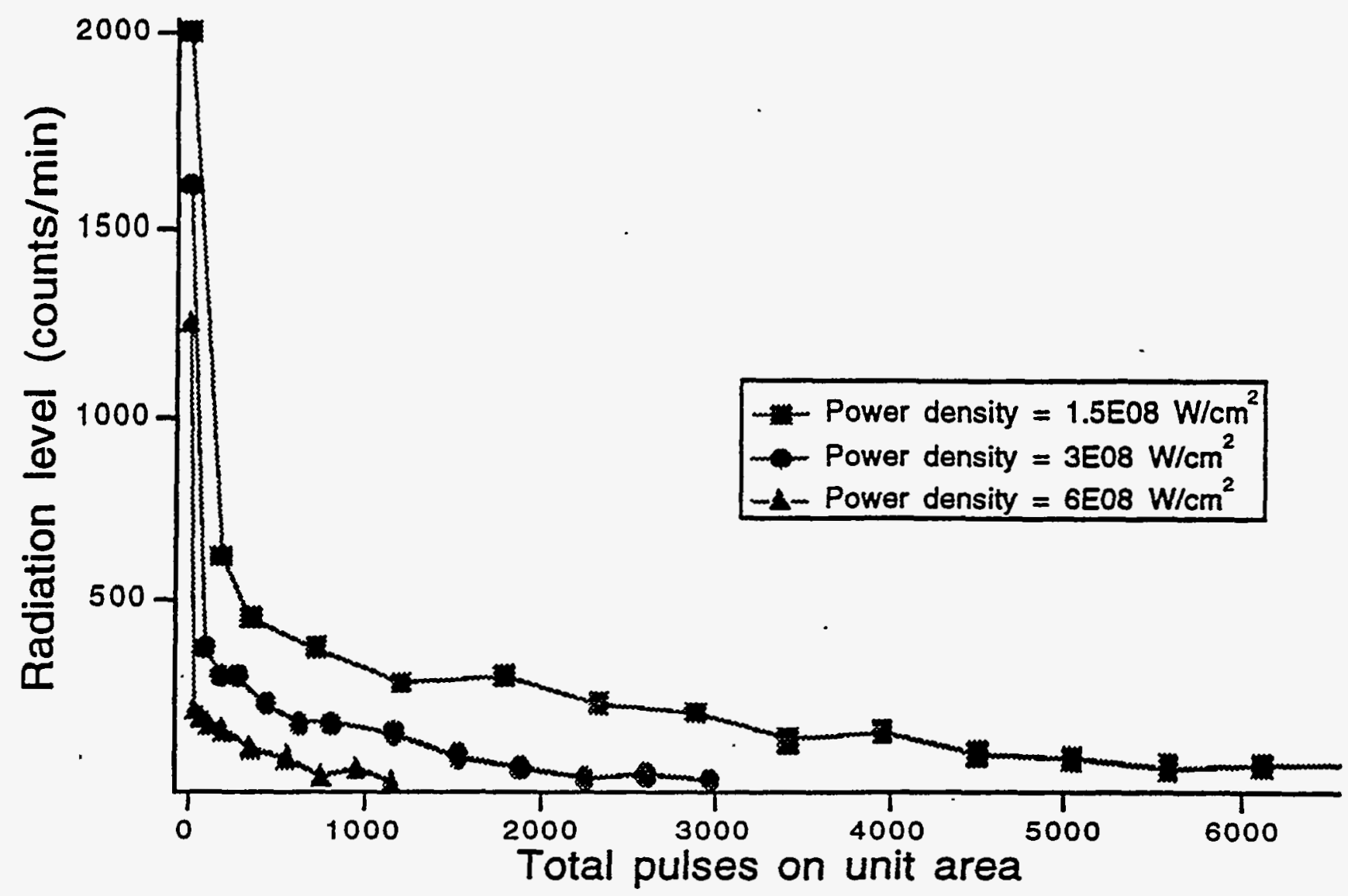

Figure A1. Variation in decontamination rate with power density (i.e.,. irradiance). These data are measured for the decontamination of WINCO SIMCON samples. The irradiance is changed by adjusting the laser spot size while keeping the repetition rate and energy/pulse constant. No correction is made for losses in energy transmission due to reflection from lens surfaces.

Note that the variation of ablated mass with laser fluence, shown in Fig. A2, is approximately linear for all wavelengths. This suggests that the results in Fig. A1 are consistent with removal of radioactive surface contaminants. Also note that there is much more effective surface ablation at lower wavelengths then at the Nd:YAG wavelength.

The fluence used in our experimentation, $-2 \mathrm{~J} \mathrm{~cm}^{-2}$, is quite a bit lower than those used in the study cited above. Assuming a laser pulse width of -25 ns for excimer laser pulses, a fluence value of 200 $\mathrm{J} / \mathrm{cm}^{2}$ translates into an irradiance of $8 E 09$ watts $/ \mathrm{cm}^{2}$ where we believe substantial plasma formation will occur. It is likely that surface decontamination efficiency will decline after plasma formation and that there is likely to be an optimum irradiance for 
decontamination. Such phenomena was reported by Walters. ${ }^{2}$

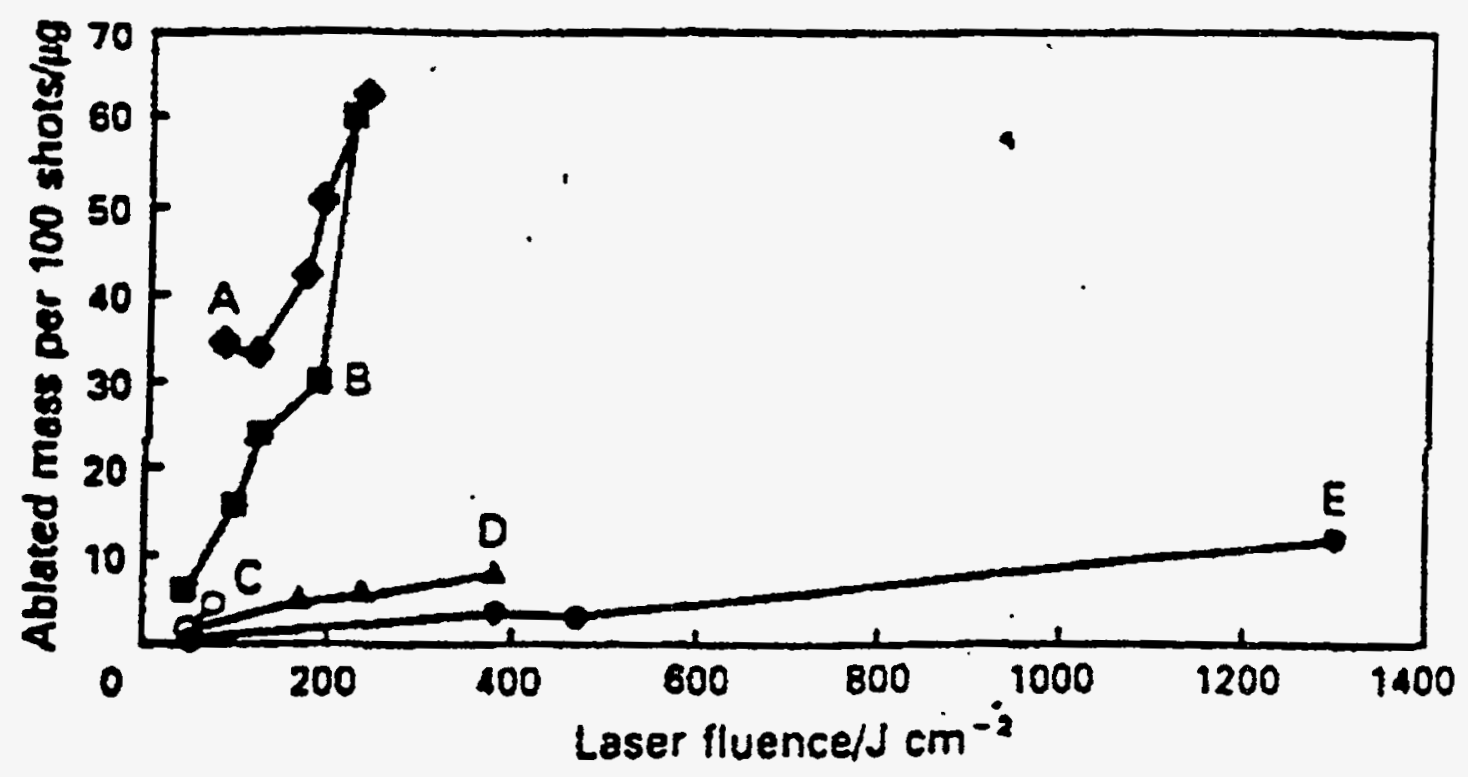

Fig. 2 Ablation efficiency (mass ablated per laser fuence) on a copper target in air buffer gas as a function of laser energy for four diferent lasers. A, ArF $193 \mathrm{~nm} ; \mathrm{B}, \mathrm{XeCl} 308 \mathrm{~nm}$; C, Nd: YAG $355 \mathrm{~nm}$; D, Nd:YAG $532 \mathrm{~nm}$; and E, Nd:YAG $1064 \mathrm{~nm}$

Figure A2. Taken from Ref. 3.

We believe that the trend toward higher efficiency at UV wavelengths, shown in Fig. A2, exists at the fluence levels we employ. To be conservative in our comparison of excimer and Nd:YAG lasers, we assume that $I_{\min }$ will go from $1 E 08 \mathrm{~W} / \mathrm{cm}^{2}$ to $5 E 08 \mathrm{~W} / \mathrm{cm}^{2}$ as we move from $248 \mathrm{~nm}$ laser radiation to $1064 \mathrm{~nm}$ laser radiation. 


\section{Calculation of Decontamination Times:}

We begin by calculating the area of the minimum irradiance beam for each laser using the parameters listed in Table 3 and equation A1:

$$
\text { Area }=E(\text { joules })^{*}(I \min )^{-1}(D t)^{-1} \text {. }
$$

For $248 \mathrm{~nm}$ radiation, $I_{\min }$ is assumed to be $1 \mathrm{E} 08$ watts $/ \mathrm{cm}^{2}$ whereas it is assumed equal to $5 E 08$ watts $/ \mathrm{cm}^{2}$ for Nd:YAG radiation at $1064 \mathrm{~nm}$.

Next, the time to decontaminate a tank is estimated using equation A2.

$$
T=\left(n p^{*} A\right) /\left(R^{*} a\right)
$$

where:

$T=$ time needed for decontamination if lasers used at minimum irradiance, $A=$ Area of tank $=4.09 \mathrm{~m}^{2}$ (sum of the interior and exterior surface areas) $\mathrm{R}=$ laser repetition rate $a=$ area irradiated by a single pulse at minimum irradiance $\mathrm{np}=$ number of pulses needed to decontaminate minimum irradiance area.

In calculations using equ. $\mathrm{A2}$, "np" is set equal to 15 . This somewhat arbitrary choice is made because real applications of laser decontamination technology require overlapping pulses onto an elementary area and revisiting areas previously treated to ensure that all contamination is removed. This particular choice is consistent with experimental work in our laboratory that shows effective decontamination at an irradiance close to the estimated minimum at $248 \mathrm{~nm}$. Since our experimental evidence suggests that raising the irradiance above the minimum value increases the amount of material ablated (see Figs. A1 and A2) in a roughly linear fashion, we can modify equation A2 to

$$
T=\left[\left(n p^{*} A\right) /\left(R^{*} a\right)\right]^{*}[I / I m i n]
$$

accommodate these facts (A3). 


\section{APPENDIX B}

Cost of Capital Equipment 


\section{Cost of capital equipment}

The cost of capital equipment for a production-scale application of LASDEC technology is estimated from the equipment used for experimentation in Ames, which is listed in Table 1. Both low- and highvalue equipment are included in the table. The lasers and optical components used for this work were not originally purchased for an industrial application and may not represent the most suitable choices for a real-world application. The estimated annual cost of capital equipment is calculated according to the formula given in Table 2. This table shows the results of the calculations performed for the Questek laser. We assume a 10-year amortization period for the non-laser components and compute the annual equipment cost as a function of the interest rate and amortization period of the laser (5 to 7 years). A range of interest rates ( 3 to $11 \%$ ) yields a range for annualized equipment costs of

1. For an excimer laser (Questek $2460 \vee \beta)$ :

$\$ 14,300$ to $\$ 22,900$

2. For a Nd:YAG laser (Continuum YG660)

$\$ 8,450$ to $\$ 13,400$

3. For a Nd:YAG laser (Continuum NY82)

$\$ 13,250$ to $\$ 21,500$

Table 1. Estimated Capital Equipment Costs for Laser Decontamination Apparatus

\begin{tabular}{|c|c|c|c|}
\hline Equipment & \begin{tabular}{|l|} 
Excimer \\
[Questek 2560vB]
\end{tabular} & \begin{tabular}{|l|} 
Nd:YAG \\
[Continuum YG660]
\end{tabular} & \begin{tabular}{|l|} 
Nd:YAG \\
[Continuum NY82]
\end{tabular} \\
\hline Laser & 560,000 & $\$ 30,000$ & 560,000 \\
\hline $\begin{array}{l}\text { 486-based computer and } \\
\text { software }\end{array}$ & 57,000 & $\$ 7,000$ & $\$ 7,000$ \\
\hline$X-Y-Z$ tables and controller & 56.500 & $\$ 6.500$ & $\$ 6.500$ \\
\hline Rotational stage and controller & $\$ 5,200$ & $\$ 5,200$ & $\$ 5,200$ \\
\hline $\begin{array}{l}\text { Cryogenic gas recirculation } \\
\text { system }\end{array}$ & 55.000 & Not required & Not required \\
\hline Energy meter & $\$ 3.000$ & $\$ 3,000$ & $\$ 3,000$ \\
\hline $\begin{array}{l}\text { Optics (mirrors and cylindrical } \\
\text { lens) }\end{array}$ & $\$ 2,100$ & $\$ 1.500$ & $\$ 1,500$ \\
\hline Optical table & $\$ 2,000$ & 52.000 & $\$ 2.000$ \\
\hline Gas regulator & $\$ 1,900$ & Not required & Not required \\
\hline Halogen gas safety cabinet & $\$ 1.700$ & Not required & Not required \\
\hline Laser displacement sensor & $\$ 1,600$ & 51.600 & $\$ 1,600$ \\
\hline Optical mounts & $\$ 1,000$ & 51.000 & $\$ 1,000$ \\
\hline Particulate collection cell & $\$ 1.000$ & $\$ 1,000$ & $\$ 1,000$ \\
\hline $\begin{array}{l}\text { TV monitor \& camera (remote } \\
\text { viewing) }\end{array}$ & $\$ 500$ & 5500 & $\$ 500$ \\
\hline $\begin{array}{l}\text { Personal safety devices } \\
\text { (hearing, eye protection) }\end{array}$ & $\$ 500$ & $\$ 500$ & $\$ 500$ \\
\hline Exhaust pump & $\$ 300$ & 5300 & $\$ 300$ \\
\hline In-line HEPA filter & $\$ 200$ & 5200 & $\$ 200$ \\
\hline Fiber-optic delivery system & N/A & 2 & $?$ \\
\hline
\end{tabular}


Table 2. Annualized excimer laser equipment costs for laser decontamination

$$
\begin{aligned}
& C_{-} E(i, n):=60000 \cdot\left[\frac{i \cdot(1+i)^{n}}{(1+i)^{n}-1}\right]+39500 \cdot\left[\frac{i \cdot(1+i)^{10}}{(1+i)^{10}-1}\right] \\
& \mathrm{n}:=1 . .10 \\
& \text { C_E }(0.03, \mathrm{a}) \\
& C_{-} E(0.07, n) \quad C_{-} E(0.11, n) \\
& 6.643 \cdot 10^{4} \\
& 6.982 \cdot 10^{4} \\
& 2.584 \cdot 10^{4} \\
& 2.077 \cdot 10^{4} \\
& 1.773 \cdot 10^{4} \\
& 1.571 \cdot 10^{4} \\
& 1.426 \cdot 10^{4} \\
& 1.318 \cdot 10^{4} \\
& 1.234 \cdot 10^{4} \\
& 1.166 \cdot 10^{4} \\
& \begin{array}{|c|}
\hline 3.881 \cdot 10^{4} \\
\hline 2.849 \cdot 10^{4} \\
\hline 2.334 \cdot 10^{4} \\
\hline 2.026 \cdot 10^{4} \\
\hline 1.821 \cdot 10^{4} \\
\hline 1.676 \cdot 10^{4} \\
\hline 1.567 \cdot 10^{4} \\
\hline 1.483 \cdot 10^{4} \\
\hline 1.417 \cdot 10^{4} \\
\hline
\end{array} \\
& \begin{array}{|l|}
\hline 7.331 \cdot 10^{4} \\
\hline 4.174 \cdot 10^{4} \\
\hline 3.126 \cdot 10^{4} \\
\hline 2.605 \cdot 10^{4} \\
\hline 2.294 \cdot 10^{4} \\
\hline 2.089 \cdot 10^{4} \\
\hline 1.944 \cdot 10^{4} \\
\hline 1.837 \cdot 10^{4} \\
\hline 1.754 \cdot 10^{4} \\
\hline 1.69 \cdot 10^{4} \\
\hline
\end{array}
\end{aligned}
$$

\section{Operating costs}

These estimated costs are based on an operating schedule of 60 hours/week, 50 weeks/year. The estimates are based either upon extrapolations of our experience or information provided by vendors.

\section{Equipment maintenance costs:}

Annual excimer laser maintenance costs are estimated assuming:

1. Replacement of the output coupler (required every two months) $\$ 2500$

2. Replacement of rear coupling mirror

3. Replacement of fan assembly (required every two years)

4. Minor supplies (e.g., filters, pump oil, pump diaphragm, etc.)

5. Thyratron (estimated replacement every four years) 
Annual Nd:YAG laser maintenance costs are estimated ${ }^{*}$ assuming:

1. Replacement of flash lamps

$\$ 1,200$ (YG660); $\$ 3,600$ (NY82)

2. Replacement of cooling water filters

3. YAG rods, mirrors, capacitors, etc.

$\$ 200$ (YG660); \$200 (NY82)

$\$ 1,500$ (YG660); $\$ 3,000$ (NY82)

Totals $=\$ 2,900$ (YG660); $\$ 6,800$ (NY82)

("see discussion on page 10 for vendor's suggestions.)

Consumable supplies:

We assume that the laser apparatuses can be positioned in close proximity to the restricted access area close to items that require decontamination. It is also assumed that electricity and cooling water can be provided at the site at no cost to the decontamination operation.

The Ames excimer laser operation consumes gases and liquid nitrogen (required for the operation of a cryogenic gas purifier). According to one excimer laser vendor (Lumonics) these costs are $-\$ 3.00 /$ hour for a $90 \mathrm{~W}$ excimer laser used on an industrial basis. The highly automated operation of most modern laser systems permits their use with only minimal supervision and they should be amenable to multi-shift operation. We assume 60 hour/week operation for 50 weeks of the year, which yields an annual gas/liquid nitrogen costs of $\$ 9,000$.

An excimer laser industry publication ${ }^{3}$ detailed recent (1993-1994) improvements in excimer laser performance. It describes a commercial excimer laser system in which the halogen gases and gas delivery system have been replaced by an on-demand pure fluorine gas generator located within the laser tube assembly. This new development in excimer laser technology offers the possibility of year-long industrial operation without any scheduled maintenance or gas replacement.

Latest advances in material technology comprising new metal alloys and ceramic technology in excimer laser cavity design provided one billion shots hands-off operation of a 50-W deep-UV excimer laser source. [Note that one billion pulses represents approximately thirty-one 60-hour weeks of $150 \mathrm{~Hz}$ excimer laser operation].. . Economically operating systems up to $500 \mathrm{~W}$ will soon become a reality.

Nd:YAG lasers do not sustain costs for replaceable gases. Flash lamps can be considered a consumable item requiring periodic replacement.

3"Lambda Highlights," No.44, May 1994, pg. 3. 
Representatives of a commercial Nd:YAG laser manufacturer were contacted and asked to comment on the Nd:YAG costs outlined in this report. They stated that ${ }^{4}$ :

We would like a minor modification to be made in the performance and cost area as mentioned in our conversation this morning. $50 \mathrm{~Hz}$ repetition rate with 1200 $\mathrm{mJ} 1064 \mathrm{~nm}$ in $9 \mathrm{~ns}$ is our standard product for over one year (Powerlite 9050). The pricing on this laser is $\$ 80,000$ with potential for $20-25$ ns operation for $1064 \mathrm{~nm}$ output only.

Annual laser maintenance costs for Nd:YAG as reported should be less due to changes in optical construction and better coating technology incorporated in the new Continuum Powerlite lasers. Greater than $10 \%$ of laser cost per year is higher than average of $5-8 \%$ taking into account 60 hours per week and 50 weeks per year [service]. One operator has [operated at] 24 hours per day for 12 day periods then [shut] down for only $24-48$ hours and repeats the cycle. This NY82 [laser] has been in operation since 1988 and operates at $80 \%$ of rated energy with flashlamp replacement every $50-70$ million shots. $100 \mathrm{~Hz}$ operation with 60W of average power is the new YAG standard for Continuum with a price of $\$ 100,000$.

Note that 24 hour/day operation at $30 \mathrm{~Hz}$ results in $\sim 30$ million shots per 12 day period and therefore flashlamps would need to be replaced roughly once per month under these conditions.

An advantage held by Nd:YAG lasers relative to excimer lasers for metal decontamination is the potential for porting Nd:YAG laser beams to remote locations with relatively inexpensive optical fibers. The fibers represent a consumable expense that we have no way to estimate on an annual basis.

\section{Labor costs:}

Annual labor costs include two components. First we assume that an employee is trained in the servicing and operation of the laser. We assume that the employee has an undergraduate education with a science major and earns $\$ 50,000$ year. Overhead and benefits add an additional $\$ 50,000$ yielding an annual "dedicated" labor cost of $\$ 100,000$.

An additional labor-related cost component will be added later to cover

${ }^{4}$ D. Black, Continuum Lasers, Carmel, IN. Private communication, August 5, 1994. 
costs associated with the alignment of laser systems within restricted environments. These costs are related to additional labor that is needed to assist the laser operator during alignment. Since there may be less maintenance associated with the use of a Nd:YAG laser relative to an excimer laser of the type used in Ames it is possible that labor costs would diminish were a laser of this type used. We, however, utilize the same labor costs for each laser in our calculations. 